\title{
ABORDAJE DE LA ANSIEDAD EN PACIENTES DIAGNOSTICADOS DE CÁNCER
}

\author{
TREATMENT OF ANXIETY IN PATIENTS WITH CANCER
}

\author{
María José Muñoz Algarl y Patricia Bernal García \\ I Instituto Psiquiátrico Montreal. El Plantío, Majadahonda. Madrid, España \\ ${ }^{2}$ Hospital Dr. Rodríguez Lafora. Madrid, España
}

Resumen

Objetivo: El diagnóstico de cáncer puede ser considerado como un potente estresor que puede provocar reacciones emocionales $\mathrm{e}$ incluso trastornos emocionales como por ejemplo, trastornos de ansiedad, del estado de ánimo o trastornos adaptativos. Dada la elevada frecuencia de patología ansiosa en pacientes con diagnóstico de cáncer, nuestro objetivo es revisar la eficacia de los tratamientos psicológicos utilizados para el abordaje de la sintomatología ansiosa en pacientes con cáncer.

Método: Se ha realizado una búsqueda bibliográfica en la base de datos PubMed mediante los términos: <anxiety treatment AND cancer>. Se analizaron artículos científicos publicados desde febrero de 2007 hasta febrero de 2016, con pacientes oncológicos como población diana.

Resultados: Se han analizado un total de 40 artículos, con homogeneidad en cuanto a diagnóstico, tipo de cáncer y sexo (mayoritariamente mujeres). 34 de los artículos demuestran ser efectivos en la reducción de la ansiedad. Las más utilizadas fueron el mindfulness, los enfoques cognitivo-conductuales y la relajación. Las terapias complementarias han demostrado resultados variables. Técnicas como el yoga fueron ineficaces.

Conclusiones: Existen múltiples opciones no farmacológicas para lograr una reducción de la ansiedad en pacientes oncológicos. La
Abstract

Objective: The diagnosis of cancer can be considered as a high stressor which produce emotional reactions and emotional disorders like anxiety disorder, mood disorder or adjustment disorder. Given the high frequency of anxious symptoms in patients with diagnosis of cancer, our objective is to review the effectiveness of the psychological treatments used to approach the anxiety in cancer patients.

Method: We performed a bibliographic review in PubMed database with the terms: <anxiety treatment AND cancer>. We analyzed scientific articles published since February 2007 to February 2016 with a sample of cancer patients.

Results: We analyzed 40 articles with homogeneity in terms of diagnosis, kind of cancer and sex (most common females). 34 of them demonstrated to be effective in reduction of anxiety (the most used were mindfulness, cognitive behavioral approaches and relaxation). The complementary therapies have demonstrated variable results. Techniques like yoga were ineffective.

Conclusion: There are multiple non farmacological options to reduce the anxiety in oncological patients. Most of techniques studied shown to be effectiveness in reduction of anxiety and achieve other benefits as reduction of depressive symptoms associated

\section{Correspondencia:}


mayoría de técnicas evaluadas demuestran eficacia para reducir la ansiedad e incluso conseguir otros beneficios como la reducción de sintomatología depresiva asociado al nuevo diagnóstico de cáncer o asociado a las intervenciones relacionadas con el cáncer.

Palabras clave: Ansiedad, cáncer, tratamiento, abordaje psicológico. with a new diagnosis of cancer or associated with medical interventions.

Keywords: Anxiety, cancer, treatment, psychological approach.

\section{INTRODUCCIÓN}

El término angustia, "angor" y "angina", provienen de una misma raíz griega o latina, y significan constricción, sofocación, estrechez u opresión, y se refieren a la sensación de opresión precordial y epigástrica con desasosiego que la caracteriza $^{(1)}$. La angustia es una manifestación emocional caracterizada por un temor a lo desconocido o a lo amenazante. Existe una angustia que puede ser considerada normal, pues aparece frente a diversos estímulos estresantes, que implican una amenaza real e imponen un desafío. Si por el contrario, la valoración de una amenaza es errónea o distorsionada o el estímulo es imaginario, se genera una angustia que tiende a persistir, transformándose en anormal o patológica. Es decir, la angustia normal se basa en preocupaciones presentes o del futuro inmediato y desaparece al resolver los problemas mientras que la angustia patológica, antes Ilamada neurótica, es desmedida y persistente, planeando un futuro incierto o amenazante y va restringiendo la autonomía y desarrollo personal de quien la sufre ${ }^{(1)}$.

\section{Ansiedad y cáncer}

El impacto que produce la palabra cáncer sobre el enfermo y su entorno familiarsocial es enorme. Se trata por tanto, de una enfermedad estigmatizante, que genera sufrimientos y cambios en la vida de las personas $^{(2)}$.

Los pacientes que han sido diagnosticados de cáncer experimentan una variedad de estados afectivos, incluyendo ansiedad y depresión que pueden verse afectados por el dolor y otros síntomas físicos derivados del cáncer y sus tratamientos ${ }^{(3)}$.

En general, el desarrollo de consecuencias emocionales negativas se van sucediendo a medida que se van comunicando los resultados de pruebas médicas (de ahí la importancia de aprender a dar malas noticias). A corto plazo, se incrementa la ansiedad de manera importante en casi un $50 \%$ de los pacientes que tienen que repetirse una prueba médica, o hacer otra que descarte el diagnóstico de cáncer. Si las nuevas pruebas arrojan resultados negativos, la ansiedad disminuirá significativamente; mientras que si hay resultados positivos (o se continúan realizando más pruebas), se mantienen los niveles altos de ansiedad. Cuando se ha confirmado el diagnóstico y se inicia el tratamiento se inicia un proceso en el cual la ansiedad suele mantenerse elevada en el tiempo. Con frecuencia, el paciente presenta un estado de alerta o amenaza y ansiedad que puede llegar a ser patológica ${ }^{(4)}$.

La prevalencia de los trastornos psicopatológicos en los pacientes con cáncer 
varía dependiendo de la metodología empleada en los estudios, siendo mayor que en la población general(5). El DSM-IV-TR recoge unas cifras de prevalencia que varía entre el 5 y el $20 \%{ }^{(6)}$.

Sin embargo, en un metaanálisis realizado por Mitchell et al. ${ }^{(7)}$ sobre 52 estudios analizados utilizando los criterios DSM, encuentran una prevalencia de trastornos adaptativos del 19,4\% (14,5-24,8), trastornos de ansiedad el $10,3 \%(5,1-17,0)$ y el $2,7 \%$ de distimia $(1,7-4,0)$. La prevalencia de cualquier tipo de depresión (mayor o distimia) combinada fue del 20,7\% (12,9$29,8)$, depresión o trastornos adaptativos $31.6 \%(25,0-38,7)$ y cualquier trastorno del ánimo, incluyendo la ansiedad, del $38,2 \%(28,4-48,6)$.

Por otro lado, Patsy et al. ${ }^{(8)}$ han encontrado en su estudio varios factores que pueden influir también los niveles de ansiedad que padece el paciente. Podría verse incrementado el riesgo de ansiedad durante el tratamiento del cáncer cuando existen los siguientes factores: historia de trastorno de ansiedad, dolor severo, ansiedad en el momento del diagnóstico, limitaciones funcionales, descenso de apoyo social, avance del trastorno o historia de trauma.

\section{Etiología de la ansiedad}

Siguiendo a Maté et al. ${ }^{(9)}$, entre las causas psicológicas más frecuentes de la sintomatología ansiógena encontramos la percepción de cercanía de la muerte; el miedo a la evolución de la enfermedad y las falsas creencias asociadas a la misma; problemas emocionales como la anticipación del sufrimiento propio y de los allegados, la dificultad para ventilar y expresar sentimientos, los temores y preocupaciones, la sensación de pérdida de control, problemas de índole espiritual y existencial, crisis de creencias, necesidad de trascendencia; y problemas del entorno como pueden ser la privación o el exceso de estimulación, el aburrimiento, la falta de cuidados o la sobreprotección familiar. También los problemas sociales de tipo económico, como son la pérdida del empleo, la situación de baja por larga enfermedad e incapacidad laboral; problemas familiares, de relación interpersonal, son una fuente importante de distrés. Sin embargo, no podemos restar importancia a las diferentes condiciones médicas como posible causa: la pérdida de vitalidad originada por la deficiencia del estado nutricional generada por los citostáticos, así como la mucositis, náuseas, anorexia y vómitos, desencadenan en los pacientes el temor a no volver a recuperar nunca el estado de salud previo.

Por último, algunos tumores cerebrales, tumores secretores de hormonas y los que por su localización invaden núcleos de síntesis hormonal, están entre los más relacionados con la generación de alteraciones afectivas y de ansiedad ${ }^{(9)}$.

Tratamiento de la ansiedad en pacientes con cáncer

Los tratamientos recomendados para el tratamiento de la ansiedad engloban medidas farmacológicas (basadas en la administración de ansiolíticos, especialmente las benzodiacepinas, cuya elección debe realizarse en función de su vida media y su potencia ansiolítica) y no farmacológicas (basadas en la psicoterapia de soporte emocional y las técnicas cognitivo-conductuales).

\section{Tratamiento psicológico}

El tratamiento psicológico es considerado como tratamiento intermedio a la intervención terapéutica propia del cáncer ${ }^{(10)}$.

Fawzy et al. ${ }^{(11)}$ señalan que el objetivo de las intervenciones psicológicas es ayudar a los pacientes de cáncer a soportar 
mejor su diagnóstico y tratamiento, disminuir los sentimientos de alienación, aislamiento, indefensión, y abandono; reducir la ansiedad en relación a los tratamientos, y clarificar percepciones e informaciones erróneas. Estas intervenciones que se diseñan para disminuir la indefensión y desesperanza tienen además la ventaja de que animan a la persona para que adopte más responsabilidad en volver a estar bien y en colaborar con los tratamientos médicos ${ }^{(12)}$.

Muchos programas de psicoterapia individual y grupal enseñan habilidades de afrontamiento específicamente diseñadas para ayudar a los pacientes a reducir síntomas asociados al cáncer como ansiedad, náuseas anticipatorias, vómitos y dolor que pueden exacerbar la respuesta emocional del paciente ${ }^{(13)}$.

A continuación, explicaremos los diferentes abordajes realizados en la actualidad para el tratamiento de la ansiedad. Analizaremos intervenciones tanto de corte psicológico como terapias alternativas.

\section{Terapia cognitiva}

Esta terapia pretende favorecer un cambio de pensamiento enfocado hacia el positivismo y la esperanza, en la manera de interpretar y entender la enfermedad por el paciente de cáncer, siempre y cuando, el paciente se encuentre invadido por pensamientos, creencias, ideas o conceptos deformados, irracionales o inapropiados acerca de su enfermedad y su verdadera situación.

En el caso de los enfermos de cáncer, los pensamientos irracionales suelen interferir en su aceptación del diagnóstico, dificultándoles seguir las prescripciones médicas y obstaculizando en algunos de ellos el participar activamente en la batalla contra la enfermedad ${ }^{(10)}$.

Vinci et al. ${ }^{(14)}$ reconocen numerosas ventajas respecto a otras terapias, ya que es limitada en el tiempo (generalmente 9-12 semanas) que trabaja en base a objetivos concretos y desarrollo de habilidades.

\section{Relajación}

Es una técnica que utiliza para contrarrestar los efectos nocivos del estrés y provocar cambios fisiológicos opuestos a los producidos en el organismo en situaciones de fuerte contenido ansiógeno( ${ }^{(15)}$. La relajación puede aprenderse mediante la práctica de diversas técnicas:

1. Respiración profunda: Según Song et al. ${ }^{(16)}$, la respiración profunda durante la quimioterapia ayuda a disminuir la ansiedad y la náusea. Es un método sencillo que ayuda a disminuir el dolor y adquirir autocontrol. Enfoca la atención, reduce la tensión muscular, relaja el diafragma y oxigena el cuerpo. Dicha técnica de relajación consiste en tensar y relajar sucesivamente distintos grupos de músculos en posición de decúbito, es una técnica útil que se puede combinar con respiración profunda y sugestión ${ }^{(17)}$.

2. Relajación muscular progresiva: Varios estudios han demostrado que la relajación muscular progresiva es efectiva para disminuir la sintomatología ansiosa, depresiva y controlar el dolor ${ }^{(15)}$. El máximo efecto se ha visto cuando se practica antes de empezar la quimioterapia ${ }^{(18)}$. El propósito es relajar los músculos progresivamente durante alternaciones de contracción y relajación de grupos de músculos aislados.

3. Imaginación guiada: Algunos estudios han demostrado que esta práctica reduce los síntomas de ansiedad, depresión y fatiga con sólo practicar tres veces por semana. En esta técnica, también conocida 
como visualización, la persona se imagina escenas, sonidos, u olores asociados con un determinado ambiente $^{(15)}$. Se basa en la idea de que la repetición continuada de aquello que queremos conseguir facilita su consecución. Combinada con otra técnicas de relajación, el empleo de la visualización es primordial en cualquier tratamiento de soporte orientado a potenciar los tratamientos contra el cáncer, evitar tanto los efectos nocivos de la enfermedad (el dolor) como los efectos del tratamiento (náuseas, vómitos, fatiga...) y favorecer la recuperación de la salud $^{(10)}$.

\section{Otras}

- La hipnosis ${ }^{(19)}$ se usa ampliamente para el control del dolor y la ansiedad en cáncer para atenuar la experiencia de sufrimiento. Consiste en lograr un estado de conciencia alterado, en focalizar la atención, disociarse de la conciencia periférica y mejorar la responsabilidad de las señales sociales. Es efectiva en el control de síntomas somáticos como el dolor y la ansiedad, y puede permitir facilitar la participación de los pacientes en procedimientos médicos.

- Reducción del estrés basado en mindfulness (MBSR): es una técnica de manejo de estrés desarroIlado por Kabat-Zinn, Lipworth y Burney $^{(20)}$ que se realiza en grupo por un instructor entrenado en 8 sesiones semanales de 2-2,5 horas con práctica de meditación mindfulness, suaves ejercicios de yoga y enseñanza psicológica y fisiológica del estrés ${ }^{(21)}$. Dicha técnica tiene origen en la filosofía budista. Su práctica regular permite cultivar la autoaceptación, mejorar las estrategias de regulación emocional y mejorar la calidad de vida, reducir pensamientos intrusivos, ansiedad y depresión ${ }^{(22)}$. El programa incluye un día completo de retiro de silencio y la recomendación de práctica diaria en casa de 45 minutos entre sesiones. El objetivo es incrementar la capacidad de los participantes para experimentar pensamientos, sentimientos y sensaciones corporales que puedan surgir, contrarrestando la evitación y desarrollando mayor tolerancia emocional. El objetivo de la práctica formal (meditación, ejercicios de respiración y yoga) e informal (meditación caminando, contemplación) del mindfulness es incrementar las habilidades de atención en los participantes para permitirles reconocer la activación automática del proceso disfuncional de pensamiento y desacoplarles de dicho proceso para redirigir su atención a la experiencia del momento presente ${ }^{(21)}$.

- Intervenciones basadas en uso de tecnología asistida ${ }^{(23)}$ : son altamente efectivos. Herramientas de apoyo a pacientes basados en uso de ordenador proporciona información, apoyo en la toma de decisiones e interacción con otros pacientes y un rendimiento no solo con aumento de conocimientos sino también mejor interacción médico-paciente y mejora el apoyo social.

- Musicoterapia: Uso de música controlada, sus elementos y sus influencias en el ser humano para ayudar en la integración fisiológica, psicológica y emocionales en el individuo durante el tratamiento de la enfermedad $^{(22)}$. 


\section{Tratamiento farmacológico}

$\mathrm{Si}$ las intervenciones psicoeducativas y psicosociales no son suficientes para tratar la ansiedad de los pacientes, puede ser necesario utilizar tratamientos farmacológicos. Desde 1980, los estudios han evaluado gran variedad de fármacos. Tras revisar la evidencia en la literatura, aquellos que probablemente sean efectivos en combinación con intervenciones psicosociales son los ansiolíticos, los antidepresivos, los antihistamínicos y los neurolépticos atípicos. Dicha recomendación es avalada por la opinión de expertos (NCCN, 2008) como por la bibliografía revisada ${ }^{(24)}$.

Los antidepresivos son útiles en el tratamiento de la depresión en general y de aquella en contexto de un cáncer. Su utilidad es disminuir los síntomas depresivos (aunque puede administrarse en personas sin amplio rango de síntomas depresivos), mejorar la capacidad funcional, reducir la caquexia, aminorar los síntomas menopáusicos y reducir el dolor. Algunos de ellos tienen también propiedades ansiolíticas y pueden usarse eficazmente en trastornos ansioso-depresivos ${ }^{(13)}$ o como tratamiento adyuvante para el dolor, nauseas y vómitos asociados al cáncer. Varios investigadores han encontrado significativa mejoría con mirtazapina, fluvoxamina o duloxetina ${ }^{(8)}$. En el caso de pacientes con insomnio también pueden beneficiarse de antidepresivos como la mirtazapina, amitriptilina o la trazodona ${ }^{(25)}$.

Por otro lado, las benzodiacepinas pueden producir alivio a corto plazo de los síntomas ansiosos, pero no es una buena estrategia en tratamientos a largo plazo dada la elevada probabilidad de habituación o dependencia ${ }^{(13)}$.

Las benzodiacepinas tienen efecto ansiolítico, sedativo y relajante muscular. Las más usadas en el paciente oncológi- co son el alprazolam, lorazepam y clonazepam. Su elección debe realizarse en función de su vida media y su potencia ansiolítica. El efecto secundario más común es la sedación y la somnolencia, así como también en personas mayores o con estados somáticos comprometidos, puede asociarse a ataxia, disartria, inestabilidad, confusión, dificultades de concentración y torpeza. Las benzodiacepinas están contraindicadas en la insuficiencia respiratoria, en el síndrome de apnea del sueño, en miastenia gravis y en determinadas encefalopatías. En pacientes con Delirium o riesgo de aparición, es preferible la utilización de neurolépticos: haloperidol 2,5-5mg/VO (la mitad por vía parenteral) o tioridazina $10-50 \mathrm{mg} / 8-12 \mathrm{~h} / \mathrm{VO}^{(9)}$.

Por último lugar, los antipsicóticos de perfil sedativo a bajas dosis, como la olanzapina o la quetiapina son efectivos en pacientes con ansiedad severa no controlada con benzodiacepinas o que no pueden tomarlas. También son útiles para pacientes con complicaciones respiratorias sin producir los efectos de depresión respiratoria que producen las benzodiacepinas ${ }^{(25)}$.

Dada la evidencia encontrada en la bibliografía de diferentes técnicas no farmacológicas para reducir la ansiedad en población oncológica, y no habiendo sido establecidas como recomendación terapéutica, planteamos un estudio que demuestre la utilidad de dichas técnicas y los beneficios en población oncológica.

\section{METODOLOGÍA}

En este trabajo se lleva a cabo una búsqueda bibliográfica en la base de datos PubMed utilizando los términos: <anxiety treatment AND cancer>. Inicialmente, se obtuvieron 8.188 referencias. De ellas, se excluyeron aquellas que no cumplían los criterios de inclusión propuestos en este 
estudio: artículos científicos escritos en lengua inglesa o castellana, publicados entre febrero de 2007 y febrero de 2016, estudios realizados en población oncológica, estudios experimentales y que aparecieran a texto completo, quedando un total de 299 artículos. De esta selección, se excluyeron los artículos que abordaban el manejo de la ansiedad con terapias farmacológicas, aquellas que evaluaban síntomas distintos a la ansiedad y los que estudiaban el efecto de la intervención en familiares o cuidadores de pacientes oncológicos como población diana, resultando un total de 40 artículos susceptibles de revisión.

\section{RESULTADOS}

La mayoría de estudios analizan muestras homogéneas en cuanto a diagnóstico y tipo de cáncer. La edad de los pacientes está comprendida en rangos de edad adulta (18-89 años de edad). Todos los estudios tienen un diseño experimental (36 de ellos utilizan un diseño tipo ensayo clínico aleatorizado prospectivo, uno realiza un estudio con diseño de casos y control, dos cuasiexperimentales y un estudio clínico pragmático).

Las terapias que estudian las diferentes publicaciones revisadas en este estudio son las siguientes:

- Intervención en Mindfulness: Encontramos 7 artículos publica$\operatorname{dos}^{(20,22,26-30)}$, de los cuales solo 5 de ellos analizan exclusivamente el efecto de la Reducción de Estrés basada en Mindfulness siguiendo el modelo de Kabat-Zinn de 8 semanas de duración (uno de ellos solo se administra durante 6 semanas). Otro estudio compara dicha técnica combinada con un programa de educación nutricional versus trata- miento estándar, frente a otro de ellos en el que se compara la técnica de Mindfulness con consultas telefónicas piscooncológicas con orientación cognitivo conductual.

- Terapia cognitivo-conductual (asociada o no a relajación): Encontramos 11 estudios que demuestran efectividad $^{(31-40)}$, ya que todas ellas reducen significativamente la ansiedad. Entre las estrategias utilizadas encontramos una basada en expresión escrita de Pennebaker que permite mejorar el estrés postraumático y el miedo a la progresión del cáncer.

- Intervención psicosocial (terapia de apoyo y expresión de emociones) ${ }^{(41,42)}$ : se reduce la ansiedad y la depresión, mejora calidad de vida y la salud global. Otro estudio demostró que las estrategias psicoeducativas no eran efectivas para reducir la ansiedad $^{(43)}$.

- Intervención psicológica de apoyo a corto plazo(44): Dos estudios abordan dicha terapia, concluyendo que reducen las cifras de ansiedad y depresión. En otro de los estudios que estudiaba una intervención psicoterapéutica breve aparecían beneficios a corto plazo pero no se mantenían los efectos.

- Terapia de resolución de problemas $^{(45)}$ : disminuye la ansiedad y el estrés.

- Intervención de apoyo diádica entre pares: Encontramos dos estudios que abordan esta terapia ${ }^{(46,47)}$. En uno de los estudios mejora la autoeficacia, pese a que mejora la ansiedad y depresión en ambos grupos, no se atribuyó dicha mejoría a la intervención. Sin embargo, en otro estudio si aparece una mejoría en la ansiedad y depresión, con 
beneficios en el trabajo con díadas (paciente-cuidador).

- Intervención enfocada en la narrativa ${ }^{(48)}$ (en la que se trabaja con las narrativas del paciente sobre su estado físico o sufrimiento asociado a la enfermedad): Mejora tanto las cifras de ansiedad como de depresión.

- Psicoterapia centrada en el significado vs terapia de apoyo $^{(49)}$ : mejora ansiedad, bienestar emocional y sentido de la vida.

- El uso de terapias complementarias y alternativas se aborda en uno de los estudios ${ }^{(50)}$ (los pacientes reciben una sola terapia semanal de arteterapia/musicoterapia/imaginación guiada/reiki/shiatsu, etc). Dicho estudio demostró eficacia al igual que otros 2 que encuentran beneficios para reducir la ansiedad mediante la hipnosis y los masajes con aromaterapia $^{(19,51)}$.

- Programa de ejercicios de yoga: Tres estudios analizan la eficacia del yoga ${ }^{(52-54)}$ (uno de ellos en modalidad Hatha), encontrando en ellos una mejoría la ansiedad, la depresión y la calidad de vida. Además, mejoró el dolor y la flexibilidad. Uno de ellos redujo la fatiga pero no modificó las cifras de ansiedad ni depresión. Sin embargo, la técnica de respiración de yoga (Pranaya$\mathrm{ma}$ ): se ha encontrado que mejora la ansiedad, calidad de vida y del sueño, pero no se han comprobado una reducción significativa.

- Musicoterapia (asociada o no a relajación muscular progresiva): En tres estudios que analizan su eficacia $^{(55-57)}$ encontramos que en todos ellos se produce reducción significativa de la ansiedad. Ambas estrategias combinadas aportan una mejoría del estado físico y psicológico del paciente durante la administración del tratamiento y una reducción de los días de estancia en el hospital.

- Entrenamiento en el manejo de estrés versus práctica de ejercicio versus estrategia combinada ${ }^{(58)}$ : Solo el tratamiento combinado demostró ser eficaz en la reducción de la respuesta de ansiedad y depresión, pero no se acompañaba de una mejora de la calidad de vida a nivel físico.

- Entrenamiento en el manejo de estrés (con relajación y estrategias de afrontamiento): Encontramos dos estudios que experimentan resultados contradictorios ${ }^{(37,59)}$, uno mejoraba la depresión y fatiga a corto plazo (no la ansiedad o insomnio), mientras que otro mejoraba la ansiedad, el estrés, la calidad de vida y la resiliencia.

- Intervención mediante grupo de apoyo complementada con relajación, ejercicio físico y danza ${ }^{(60)}$ : demostró ser efectiva en la reducción de la ansiedad pero no modificó los síntomas depresivos. Sin embargo, dicha intervención de apoyo realizada de forma aislada en momentos puntuales del tratamiento del paciente no demostró efecto alguno en la respuesta de ansiedad.

- Por último, sólo un estudio abordó la realización de ejercicio en el hogar basado en caminar ${ }^{(61)}$ con buenos resultados en las cifras de ansiedad.

En la tabla 1 presentamos un resumen con los estudios revisados. En ella, se recoge un análisis sobre la efectividad de las diferentes intervenciones sobre la respuesta de ansiedad. Además, se analizan también otros efectos beneficiosos asociados a cada una de ellas. 
Tabla 1. Resultados de los estudios revisados

\begin{tabular}{|c|c|c|c|c|c|c|}
\hline $\begin{array}{l}\text { ARTÍCULO } \\
\text { REVISIÓN }\end{array}$ & $\begin{array}{l}\text { ESTRATEGIA } \\
\text { EVALUADA }\end{array}$ & $\begin{array}{c}\text { MUESTRA A } \\
\text { ESTUDIO }\end{array}$ & $\begin{array}{l}\text { TIPO DE } \\
\text { ESTUDIO }\end{array}$ & $\begin{array}{l}\text { CARACTERÍSTICAS DE } \\
\text { LA INTERVENCIÓN EN } \\
\text { GRUPO EXPERIMENTAL }\end{array}$ & $\begin{array}{l}\text { CARACTERÍSTICAS } \\
\text { DE LA } \\
\text { INTERVENCIÓN EN } \\
\text { GRUPO CONTROL }\end{array}$ & $\begin{array}{l}\text { RESULTADOS } \\
\text { OBTENIDOS POST- } \\
\text { INTERVENCIÓN }\end{array}$ \\
\hline $\begin{array}{l}\text { Wilkinson } \\
\text { et al. } \\
2007^{(51)}\end{array}$ & $\begin{array}{l}\text { Masaje con } \\
\text { aromaterapia }\end{array}$ & $\begin{array}{l}288 \text { pacientes } \\
\text { diagnosticados de } \\
\text { cáncer, de los cua- } \\
\text { les } 144 \text { recibieron } \\
\text { intervención y } 144 \\
\text { fueron al grupo } \\
\text { control. Edad me- } \\
\text { dia: } 51 \text { años. }\end{array}$ & $\begin{array}{l}\text { Ensayo clínico } \\
\text { multicéntrico } \\
\text { aleatorizado } \\
\text { controlado }\end{array}$ & $\begin{array}{l}\text { Recibieron un curso se- } \\
\text { manal durante } 4 \text { semanas } \\
\text { consecutivas, con sesio- } \\
\text { nes de masaje con aro- } \\
\text { materapia durante } 1 \text { hora } \\
\text { cada una. }\end{array}$ & Tratamiento estándar & $\begin{array}{l}\text { El masaje con aromatera- } \\
\text { pia no pareció beneficio- } \\
\text { so para reducir la ansie- } \\
\text { dad y/o depresión en pa- } \\
\text { cientes con cáncer a largo } \\
\text { plazo, pero se asocia con } \\
\text { un importante beneficio } \\
\text { clínico } 2 \text { semanas des- } \\
\text { pués de la intervención. }\end{array}$ \\
\hline $\begin{array}{l}\text { Elkins et al. } \\
2008^{(19)}\end{array}$ & $\begin{array}{l}\text { Intervención } \\
\text { en hipnosis }\end{array}$ & $\begin{array}{l}60 \text { mujeres diag- } \\
\text { nosticadas de } \\
\text { cáncer de mama } \\
\text { en tratamiento con } \\
\text { tamoxifeno, >18 } \\
\text { años de edad. }\end{array}$ & $\begin{array}{l}\text { Ensayo clínico } \\
\text { prospectivo } \\
\text { aleatorizado. }\end{array}$ & $\begin{array}{l}5 \text { sesiones semanales de } \\
\text { hipnosis durante aproxi- } \\
\text { madamente } 50 \text { minutos } \\
\text { cada una. Se administra- } \\
\text { ban instrucciones para } \\
\text { poder practicar autohip- } \\
\text { nosis en casa. }\end{array}$ & Tratamiento estándar & $\begin{array}{l}\text { El grupo que recibió hip- } \\
\text { nosis presentó una mejo- } \\
\text { ría en la ansiedad, depre- } \\
\text { sión, en la interferencia } \\
\text { de los sofocos en las acti- } \\
\text { vidades diarias y el sueño } \\
\text { respecto al grupo control. }\end{array}$ \\
\hline $\begin{array}{l}\text { Antoni et } \\
\text { al. } 2009^{(40)}\end{array}$ & $\begin{array}{lr}\text { Manejo cog- } \\
\text { nitivo con- } \\
\text { ductual del } \\
\text { estrés }\end{array}$ & $\begin{array}{l}128 \text { mujeres diag- } \\
\text { nosticadas de } \\
\text { cáncer de mama } \\
\text { en estadío I-III, } \\
\text { entre 4-8 semanas } \\
\text { post-cirugía (63 } \\
\text { recibieron la inter- } \\
\text { vención, } 65 \text { eran } \\
\text { controles). Edad: } \\
\text { 18-70 años. }\end{array}$ & $\begin{array}{l}\text { Ensayo clínico } \\
\text { prospectivo } \\
\text { aleatorizado }\end{array}$ & $\begin{array}{l}\text { Se administró durante un } \\
\text { período de } 10 \text { semanas. } \\
\text { Se realizaron técnicas de } \\
\text { reducción de estrés me- } \\
\text { diante explicaciones di- } \\
\text { dácticas, ejercicios expe- } \\
\text { rienciales de role playing } \\
\text { y relajación }(2 \mathrm{~h} c / \mathrm{u}) \text {. }\end{array}$ & $\begin{array}{l}1 \text { día de psicoeduca- } \\
\text { ción concentrada en } \\
5-6 \text { horas. }\end{array}$ & $\begin{array}{l}\text { Mejor adaptación psi- } \\
\text { cológica y psicosocial } \\
\text { (reducción de la ansie- } \\
\text { dad y de los marcadores } \\
\text { específicos de cáncer) en } \\
\text { el grupo de intervención. } \\
\text { Se ha visto que facilita un } \\
\text { "mantenimiento de la re- } \\
\text { cuperación". }\end{array}$ \\
\hline $\begin{array}{l}\text { Pitceathly } \\
\text { et al } 2009 \\
\text { (41) }\end{array}$ & $\begin{array}{l}\text { Intervención } \\
\text { psicológica } \\
\text { breve }\end{array}$ & $\begin{array}{l}465 \text { pacientes } \\
\text { diagnosticados de } \\
\text { cáncer: } 154 \text { con- } \\
\text { troles, } 156 \text { inter- } \\
\text { vención inmediata } \\
\text { (al inicio de tto del } \\
\text { cáncer), } 155 \text { inter- } \\
\text { vención tardía (8 } \\
\text { semanas tras inicio } \\
\text { del tto del cáncer). } \\
\text { Edad: } 18-70 \text { años }\end{array}$ & $\begin{array}{l}\text { Ensayo clínico } \\
\text { prospectivo } \\
\text { controlado ran- } \\
\text { domizado }\end{array}$ & $\begin{array}{l}\text { Se administraron } 3 \text { sesio- } \\
\text { nes estructuradas durante } \\
\text { un período de } 6 \text { semanas. } \\
\text { Los primeros } 90 \text { minutos } \\
\text { de la sesión eran cara a } \\
\text { cara con el terapeuta, las } \\
\text { siguientes sesiones ( } 2 \text { y } \\
6 \text { semanas más tarde), se } \\
\text { realizaron telefónicamen- } \\
\text { te en } 45 \text { min. }\end{array}$ & Tratamiento estándar & $\begin{array}{l}\text { Los pacientes de alto } \\
\text { riesgo de sufrir ansiedad } \\
\text { y los que recibieron la } \\
\text { intervención era menos } \\
\text { probable que desarrolla- } \\
\text { ran ansiedad o depresión } \\
\text { comparado con tto están- } \\
\text { dar. En pacientes de bajo } \\
\text { riesgo, no hubo diferen- } \\
\text { cias entre ambos grupos. }\end{array}$ \\
\hline $\begin{array}{l}\text { Girgis et al. } \\
2009^{(42)}\end{array}$ & $\begin{array}{l}\text { Intervención } \\
\text { de apoyo } \\
\text { (entrevista } \\
\text { con asistente } \\
\text { social versus } \\
\text { médico on- } \\
\text { cólogo/gene- } \\
\text { ral versus tto } \\
\text { estándar) }\end{array}$ & $\begin{array}{l}356 \text { pacientes con } \\
\text { cáncer de mama } \\
\text { y colorrectal no } \\
\text { localizado (117 } \\
\text { controles, } 120 \text { en- } \\
\text { trevista telefónica } \\
\text { asistida por orde- } \\
\text { nador y } 119 \text { con } \\
\text { oncólogo o médi- } \\
\text { co general). Edad: } \\
28-75 \text { años. }\end{array}$ & $\begin{array}{l}\text { Ensayo clínico } \\
\text { aleatorizado } \\
\text { controlado }\end{array}$ & $\begin{array}{l}\text { Los pacientes reciben } \\
\text { una llamada enfocada en } \\
\text { counseling por parte de } \\
\text { enfermeras de oncología } \\
\text { que separan a pacientes } \\
\text { en los } 3 \text { grupos: asisten- } \\
\text { te social, oncólogo o } \\
\text { médico familia o grupo } \\
\text { control. Se realizan } 3 \\
\text { mediciones o feedback en } \\
\text { cada grupo: basal, a los } 3 \\
\text { y a los } 6 \text { meses. }\end{array}$ & Tratamiento estándar & $\begin{array}{l}\text { No se observó ningún } \\
\text { efecto en las interven- } \\
\text { ciones (respecto a la } \\
\text { ansiedad o calidad de } \\
\text { vida). Los participantes } \\
\text { del grupo de asistentes } \\
\text { sociales era más proba- } \\
\text { ble que hablaran de sus } \\
\text { necesidades y pensaban } \\
\text { que esto permitía mejorar } \\
\text { la comunicación con el } \\
\text { equipo que le trata. }\end{array}$ \\
\hline $\begin{array}{l}\text { Breitbart et } \\
\text { al. } 2010^{(49)}\end{array}$ & $\begin{array}{l}\text { Psicoterapia } \\
\text { centrada en } \\
\text { el significado } \\
\text { versus psi- } \\
\text { coterapia de } \\
\text { apoyo }\end{array}$ & $\begin{array}{l}90 \text { pacientes con } \\
\text { tumores sólidos } \\
\text { avanzados o Lin- } \\
\text { foma no Hodgkin } \\
\text { (estadio III-IV), con } \\
\text { edad: } 21-84 \text { años. } \\
49 \text { recibieron } \\
\text { intervención y } 41 \\
\text { se asignaron al } \\
\text { grupo control. }\end{array}$ & $\begin{array}{l}\text { Ensayo clínico } \\
\text { aleatorizado } \\
\text { controlado }\end{array}$ & $\begin{array}{l}\text { La intervención duró } 8 \\
\text { semanas, una psicotera- } \\
\text { pia influenciada por los } \\
\text { trabajos de Viktor Frankl } \\
\text { que utiliza didáctica, } \\
\text { discusión y ejercicios ex- } \\
\text { perienciales enfocados en } \\
\text { temas sobre el significado } \\
\text { y cáncer avanzado. }\end{array}$ & $\begin{array}{l}\text { Grupo de psicotera- } \\
\text { pia de apoyo. }\end{array}$ & $\begin{array}{l}\text { El grupo de psicoterapia } \\
\text { centrada en el significado } \\
\text { produjo beneficios signi- } \\
\text { ficativos en el bienestar } \\
\text { espiritual y sentido de la } \\
\text { vida. Mejoró significati- } \\
\text { vamente la ansiedad. En } \\
\text { el grupo control no tuvo } \\
\text { cambios significativos. }\end{array}$ \\
\hline
\end{tabular}




\begin{tabular}{|c|c|c|c|c|c|c|}
\hline $\begin{array}{l}\text { Beard et al. } \\
2011^{(39)}\end{array}$ & $\begin{array}{l}\text { Terapia de } \\
\text { relajación } \\
\text { con reestruc- } \\
\text { turación cog- } \\
\text { nitiva versus } \\
\text { Reiki vs tto } \\
\text { estandar. }\end{array}$ & $\begin{array}{l}54 \text { hombres } \\
\text { diagnosticados de } \\
\text { cáncer de prós- } \\
\text { tata, con más de } \\
30 \text { años. Fueron } \\
\text { randomizados en } \\
3 \text { grupos: } 18 \text { en } \\
\text { grupo de terapia, } \\
18 \text { en grupo de } \\
\text { Reiki y } 18 \text { con- } \\
\text { troles. }\end{array}$ & $\begin{array}{l}\text { Ensayo clínico } \\
\text { prospectivo ran- } \\
\text { domizado con } 2 \\
\text { ramas de trata- } \\
\text { miento y una de } \\
\text { control. }\end{array}$ & $\begin{array}{l}\text { Las sesiones de Reiki se } \\
\text { realizan dos veces por se- } \\
\text { mana durante } 8 \text { semanas } \\
\text { consecutivas (máximo de } \\
16 \text { sesiones). } \\
\text { La terapia de relajación } \\
\text { se realiza una vez por se- } \\
\text { mana durante } 8 \text { semanas } \\
\text { (aunque se recomienda } \\
\text { la práctica diaria de } \\
\text { relajación). La terapia } \\
\text { cognitiva es realizada por } \\
\text { un psicólogo. }\end{array}$ & Tratamiento estándar & $\begin{array}{l}\text { Ambos grupos que } \\
\text { reciben intervención } \\
\text { redujeron sus niveles de } \\
\text { ansiedad, se redujeron } \\
\text { cifras depresivas aquellos } \\
\text { pacientes que estaban } \\
\text { deprimidos al inicio y } \\
\text { también se produjo una } \\
\text { mejoría en el sentido de } \\
\text { bienestar emocional. }\end{array}$ \\
\hline $\begin{array}{l}\text { Loprinzi } \\
\text { et al. } \\
2011^{(59)}\end{array}$ & $\begin{array}{l}\text { Entrenamien- } \\
\text { to en estrés } \\
\text { y resiliencia } \\
\text { (SMART) }\end{array}$ & $\begin{array}{l}24 \text { pacientes } \\
\text { con cáncer de } \\
\text { mama: } 12 \text { pacien- } \\
\text { tes recibiendo } \\
\text { intervención y } 12 \\
\text { controles. Edad: } \\
\text { 46-75 años. }\end{array}$ & $\begin{array}{l}\text { Ensayo prospec- } \\
\text { tivo aleatoriza- } \\
\text { do controlado } \\
\text { simple ciego. }\end{array}$ & $\begin{array}{l}\text { El programa consiste en } \\
2 \text { sesiones de entrena- } \\
\text { miento de } 90 \text { minutos } \\
\text { (intervención estructura- } \\
\text { da breve en relajación- } \\
\text { meditación), una sesión } \\
\text { individual breve y } 3 \text { lla- } \\
\text { madas telefónicas de se- } \\
\text { guimiento. }\end{array}$ & Tratamiento estándar & $\begin{array}{l}\text { Mejoría de las medidas de } \\
\text { ansiedad, estrés. resilien- } \\
\text { cia y calidad de vida en el } \\
\text { grupo experimental. }\end{array}$ \\
\hline $\begin{array}{l}\text { Goerling, et } \\
\text { al. } 2011^{(43)}\end{array}$ & $\begin{array}{l}\text { Intervención } \\
\text { psicoonco- } \\
\text { lógica de } \\
\text { apoyo a corto } \\
\text { plazo }\end{array}$ & $\begin{array}{l}131 \text { pacientes } \\
\text { oncológicos } \\
\text { divididos en dos } \\
\text { grupos de alto } \\
\text { y bajo riesgo de } \\
\text { recurrencia de } \\
\text { cáncer, que a su } \\
\text { vez se randomizan } \\
\text { en grupo experi- } \\
\text { mental y control. } \\
\text { Edad: } 18-79 \text { años }\end{array}$ & $\begin{array}{l}\text { Ensayo prospec- } \\
\text { tivo aleatoriza- } \\
\text { do controlado }\end{array}$ & $\begin{array}{l}4 \text { intervenciones de pro- } \\
\text { medio en cada paciente } \\
\text { de unos } 40 \text { minutos de } \\
\text { duración durante el ingre- } \\
\text { so hospitalario. }\end{array}$ & Tratamiento estándar & $\begin{array}{l}\text { Reducción de niveles de } \\
\text { ansiedad y depresión en } \\
\text { pacientes de alto riesgo } \\
\text { tras la intervención psico- } \\
\text { lógica y } 1 \text { año tras el alta. }\end{array}$ \\
\hline $\begin{array}{l}\text { Lee et al. } \\
2012^{(57)}\end{array}$ & $\begin{array}{l}\text { Musicote- } \\
\text { rapia versus } \\
\text { relajación } \\
\text { muscular } \\
\text { progresiva. }\end{array}$ & $\begin{array}{l}40 \text { mujeres con } \\
\text { cáncer de mama } \\
\text { y ginecológicos } \\
\text { (ovario y cervi- } \\
\text { cal) que reciben } \\
\text { quimioterapia, } \\
\text { aleatorizados en } \\
\text { dos grupos de } 20 \\
\text { pacientes. Edad: } \\
\text { 27-65 años. }\end{array}$ & $\begin{array}{l}\text { Estudio piloto } \\
\text { aleatorizado en } \\
2 \text { ramas de tra- } \\
\text { tamiento. }\end{array}$ & $\begin{array}{l}\text { Se administraban las ins- } \\
\text { trucciones para la relaja- } \\
\text { ción muscular progresiva } \\
\text { durante un período de } 30 \\
\text { minutos encontrándose } \\
\text { en posición supina con } \\
\text { los ojos cerrados. Estas se } \\
\text { administraban tras cada } \\
\text { quimioterapia, por un } \\
\text { mínimo de } 6 \text { veces (cada } \\
3 \text { semanas) hasta } 9 \text { veces } \\
\text { (cada } 2 \text { semanas). }\end{array}$ & $\begin{array}{l}\text { En posición supina } \\
\text { se administraba la } \\
\text { musicoterapia du- } \\
\text { rante } 30 \text { minutos tras } \\
\text { cada quimioterapia, } \\
\text { por un mínimo de } \\
\text { 6-9 veces (cada 2-3 } \\
\text { semanas). }\end{array}$ & $\begin{array}{l}\text { Ambas estrategias son } \\
\text { útiles en la reducción de } \\
\text { la ansiedad. Ambas estra- } \\
\text { tegias mejoran los estados } \\
\text { físicos y psicológicos du- } \\
\text { rante la quimioterapia. }\end{array}$ \\
\hline $\begin{array}{l}\text { Hoffman, et } \\
\text { al. } 2012^{(29)}\end{array}$ & $\begin{array}{l}\text { Mindfulness } \\
\text { (MBSR) }\end{array}$ & $\begin{array}{l}229 \text { mujeres con } \\
\text { cáncer de mama } \\
\text { tras } 2-24 \text { meses de } \\
\text { recibir Cx, Qt y } \\
\text { Rt (estadios 0-III) } \\
\text { (18-80 años). } 114 \\
\text { grupo experimen- } \\
\text { tal y } 115 \text { grupo } \\
\text { control. }\end{array}$ & $\begin{array}{l}\text { Ensayo aleatori- } \\
\text { zado controlado }\end{array}$ & $\begin{array}{l}8 \text { semanas de sesiones. } \\
\text { Grupos de } 12-20 \text { pacien- } \\
\text { tes. Duración de } 2 \text { horas } \\
\text { aproximadamente cada } \\
\text { sesión }+45 \mathrm{~min} / \text { día en } \\
\text { casa. }\end{array}$ & Tratamiento estándar & $\begin{array}{l}\text { Mejoría significativa en } \\
\text { ansiedad, síntomas depre- } \\
\text { sivos, fatiga y calidad de } \\
\text { vida en el grupo experi- } \\
\text { mental. }\end{array}$ \\
\hline $\begin{array}{l}\text { Hirai et al. } \\
2012^{(45)}\end{array}$ & $\begin{array}{l}\text { Terapia de } \\
\text { resolución de } \\
\text { problemas }\end{array}$ & $\begin{array}{l}36 \text { mujeres con } \\
\text { cáncer de mama } \\
\text { postcirugía de } \\
\text { entre } 20-70 \text { años } \\
\text { de edad. }\end{array}$ & $\begin{array}{l}\text { Ensayo clínico } \\
\text { fase Il. }\end{array}$ & $\begin{array}{l}5 \text { sesiones semanales de } \\
1 \text { hora de duración en las } \\
\text { que se enseña estrategias } \\
\text { estructuradas para la reso- } \\
\text { lución de problemas (eva- } \\
\text { luar problemas, establecer } \\
\text { metas, generar soluciones } \\
\text { y evaluar resultados). }\end{array}$ & No hay grupo control & $\begin{array}{l}\text { Se produjo disminución } \\
\text { de los síntomas de ansie- } \\
\text { dad y estrés. Significativa } \\
\text { reducción del malestar } \\
\text { psicológico. }\end{array}$ \\
\hline
\end{tabular}




\begin{tabular}{|c|c|c|c|c|c|c|}
\hline $\begin{array}{l}\text { Lix et al } \\
2012^{(56)}\end{array}$ & $\begin{array}{l}\text { Musicote- } \\
\text { rapia }\end{array}$ & $\begin{array}{l}120 \text { mujeres con } \\
\text { cáncer de mama } \\
\text { tras mastectomía } \\
\text { radical, } 60 \text { fueron } \\
\text { asignadas al grupo } \\
\text { experimental y } 60 \\
\text { al control. Edad: } \\
25-65 \text { años. }\end{array}$ & $\begin{array}{l}\text { Ensayo prospec- } \\
\text { tivo aleatoriza- } \\
\text { do controlado }\end{array}$ & $\begin{array}{l}\text { La musicoterapia se ad- } \\
\text { ministra desde el primer } \\
\text { día postmastectomía } \\
\text { radical hasta el tercer in- } \\
\text { greso para administración } \\
\text { de quimioterapia en el } \\
\text { hospital, } 2 \text { veces/día ( } 30 \\
\text { minutos por sesión), tem- } \\
\text { prano de } 6-8 \text { a.m. y en la } \\
\text { tarde 9-11p.m. La música } \\
\text { comprende: músicas del } \\
\text { mundo, folk, recomenda- } \\
\text { das por Asociación Ame- } \\
\text { ricana de Musicoterapia y } \\
\text { de relajación. }\end{array}$ & Tratamiento estándar & $\begin{array}{l}\text { Reducción significativa } \\
\text { de la ansiedad con musi- } \\
\text { coterapia. }\end{array}$ \\
\hline $\begin{array}{l}\text { Granstam } \\
\text { et al. } \\
2012^{(60)}\end{array}$ & $\begin{array}{l}\text { Intervención } \\
\text { mediante } \\
\text { grupo de } \\
\text { apoyo }\end{array}$ & $\begin{array}{l}382 \text { mujeres con } \\
\text { cáncer de mama, } \\
191 \text { fueron asig- } \\
\text { nadas al grupo ex- } \\
\text { perimental ( } 81 \text { con } \\
\text { Qt y } 110 \text { sin Qt) y } \\
191 \text { al grupo con- } \\
\text { trol (80 con Qt y } \\
111 \text { sin Qt). Edad: } \\
\text { 30-84 años }\end{array}$ & $\begin{array}{l}\text { Ensayo prospec- } \\
\text { tivo aleatoriza- } \\
\text { do controlado } \\
\text { ( } 4 \text { ramas de tra- } \\
\text { tamiento) }\end{array}$ & $\begin{array}{l}\text { Es un programa de apoyo } \\
\text { complementada con re- } \\
\text { lajación, Qi-gong, danza } \\
\text { liberadora y ejercicio fí- } \\
\text { sico. La rehabilitación se } \\
\text { llevo a cabo durante una } \\
\text { semana en una zona resi- } \\
\text { dencial seguido de } 4 \text { días } \\
\text { de seguimiento dos meses } \\
\text { más tarde. }\end{array}$ & Tratamiento estándar & $\begin{array}{l}\text { Reducción en los niveles } \\
\text { de ansiedad en el tiempo } \\
\text { en el grupo de interven- } \\
\text { ción. No hubo cambios } \\
\text { en depresión. }\end{array}$ \\
\hline $\begin{array}{l}\text { Bränström } \\
\text { et al. } \\
2012^{(30)}\end{array}$ & Mindfulness & $\begin{array}{l}71 \text { pacientes diag- } \\
\text { nosticados de cán- } \\
\text { cer: } 32 \text { en el grupo } \\
\text { de intervención } \\
\text { y } 39 \text { en el grupo } \\
\text { control. Edad: } 30- \\
65 \text { años }\end{array}$ & $\begin{array}{l}\text { Ensayo prospec- } \\
\text { tivo aleatoriza- } \\
\text { do controlado }\end{array}$ & $\begin{array}{l}\text { La intervención se realizó } \\
\text { en sesiones semanales de } \\
2 \text { horas de duración. Con- } \\
\text { siste en ejercicios en gru- } \\
\text { po experiencial (versión } \\
\text { modificada de programa } \\
\text { desarrollado por Jon Ka- } \\
\text { bat-Zinn y colegas. }\end{array}$ & Tratamiento estándar & $\begin{array}{l}\text { Notable tendencia de } \\
\text { gran reducción en el es- } \\
\text { trés percibido y ansiedad. } \\
\text { La práctica de meditación } \\
\text { continuada se asocia con } \\
\text { reducción significativa de } \\
\text { síntomas de estrés pos- } \\
\text { traumático y evitación. }\end{array}$ \\
\hline $\begin{array}{l}\text { Greer et al. } \\
2012^{(38)}\end{array}$ & $\begin{array}{l}\text { Terapia } \\
\text { Cognitivo- } \\
\text { Conductual } \\
\text { Breve }\end{array}$ & $\begin{array}{l}40 \text { pacientes } \\
\text { diagnosticados } \\
\text { de un tumor sóli- } \\
\text { do incurable con } \\
\text { elevada ansiedad, } \\
\text { se aleatorizan } 20 \\
\text { pacientes al grupo } \\
\text { experimental y } 20 \\
\text { al grupo control. } \\
\text { Edad: } 31-81 \text { años. }\end{array}$ & $\begin{array}{l}\text { Estudio piloto } \\
\text { aleatorizado } \\
\text { controlado. }\end{array}$ & $\begin{array}{l}\text { Se administraron 6-7 } \\
\text { sesiones de terapia cog- } \\
\text { nitivo-conductual admi- } \\
\text { nistradas semanalmente } \\
\text { siempre que fuera posible } \\
\text { (la } 7^{\mathrm{a}} \text { era opcional) y se- } \\
\text { gún las necesidades de } \\
\text { los pacientes. Consta de } \\
4 \text { módulos en los cuales } \\
\text { se da información sobre } \\
\text { el concepto de ansiedad, } \\
\text { entrenamiento en relaja- } \\
\text { ción, afrontamiento del } \\
\text { miedo al cáncer y pla- } \\
\text { near/estimular para reali- } \\
\text { zar actividades. }\end{array}$ & Tratamiento estándar & $\begin{array}{l}\text { La TCC breve produjo } \\
\text { mejoría significativa en } \\
\text { cifras de ansiedad. No } \\
\text { hay cambios respecto a la } \\
\text { depresión. }\end{array}$ \\
\hline $\begin{array}{l}\text { Dhruva } \\
\text { et al. } \\
2012^{(54)}\end{array}$ & $\begin{array}{l}\text { Técnicas de } \\
\text { respiración } \\
\text { de yoga } \\
\text { (Pranayama) }\end{array}$ & $\begin{array}{l}16 \text { pacientes con } \\
\text { cáncer: } 8 \text { pacien- } \\
\text { tes en grupo expe- } \\
\text { rimental y } 8 \text { grupo } \\
\text { control. }\end{array}$ & $\begin{array}{l}\text { Estudio piloto } \\
\text { aleatorizado } \\
\text { controlado. }\end{array}$ & $\begin{array}{l}\text { La intervención Pranaya- } \\
\text { ma consiste en } 4 \text { técnicas } \\
\text { de respiración en clases } \\
\text { semanales practicadas en } \\
\text { el domicilio (60minutos } \\
\text { una vez a la semana y dos } \\
\text { veces al día en domicilio } \\
\text { durante } 20-30 \mathrm{~min} / \text { día). } \\
\text { Los pacientes recibieron } \\
\text { esta técnica durante } 2 \\
\text { ciclos consecutivos de } \\
\text { quimioterapia. El grupo } \\
\text { control recibe cuidados } \\
\text { habituales y pranayama } \\
\text { solo durante el } 2^{\circ} \text { ciclo de } \\
\text { quimioterapia. }\end{array}$ & Tratamiento estándar & $\begin{array}{l}\text { La técnica de yoga podría } \\
\text { mejorar las alteraciones } \\
\text { del sueño, la ansiedad y } \\
\text { calidad de vida. }\end{array}$ \\
\hline
\end{tabular}




\begin{tabular}{|c|c|c|c|c|c|c|}
\hline $\begin{array}{l}\text { Mattsson } \\
\text { et al. } \\
2013^{(23)}\end{array}$ & $\begin{array}{l}\text { U-CARE ver- } \\
\text { sus TCC }\end{array}$ & $\begin{array}{l}\text { Cáncer de mama, } \\
\text { colorrectal y de } \\
\text { próstata. Se rando- } \\
\text { mizan } 20 \text { pacien- } \\
\text { tes en grupo expe- } \\
\text { rimental y grupo } \\
\text { control. }\end{array}$ & $\begin{array}{l}\text { Ensayo prospec- } \\
\text { tivo aleatoriza- } \\
\text { do controlado }\end{array}$ & $\begin{array}{l}24 \text { meses usando progra- } \\
\text { ma U-CARE (plataforma } \\
\text { de internet psicoeducati- } \\
\text { va: técnicas de relajación, } \\
\text { ejercicio físico, dieta salu- } \\
\text { dable y hábitos de sueño/ } \\
\text { act. saludables) } \\
\text { La TCC se administró en } \\
10 \text { sesiones administradas } \\
\text { durante } 24 \text { meses. }\end{array}$ & No hay grupo control & $\begin{array}{l}\text { Ambos grupos presentan } \\
\text { mejoría en ansiedad y } \\
\text { depresión. }\end{array}$ \\
\hline $\begin{array}{l}\text { Guo et al. } \\
2013^{(34)}\end{array}$ & $\begin{array}{l}\text { Intervención } \\
\text { psicosocial } \\
\text { (Psicoedu- } \\
\text { cación, TCC } \\
\text { y terapia de } \\
\text { apoyo y ex- } \\
\text { presión de } \\
\text { emociones) }\end{array}$ & $\begin{array}{l}178 \text { pacientes con } \\
\text { cáncer no metastá- } \\
\text { sicos: nasofaríngeo, } \\
\text { mama, ginecoló- } \\
\text { gicos, pulmón y } \\
\text { otros ( } 89 \text { pacientes } \\
\text { en grupo experi- } \\
\text { mental, } 89 \text { en gru- } \\
\text { po control). Edad } \\
\text { comprendidas entre } \\
20-79 \text { años }\end{array}$ & $\begin{array}{l}\text { Ensayo prospec- } \\
\text { tivo aleatoriza- } \\
\text { do controlado }\end{array}$ & $\begin{array}{l}\text { Se lleva a cabo en grupos } \\
\text { de } 5-8 \text { pacientes durante } \\
60 \text { minutos en entrevistas } \\
\text { cara a casa semanales. } \\
\text { En total: } 8-12 \text { horas de } \\
\text { terapia. }\end{array}$ & Tratamiento estándar & $\begin{array}{l}\text { Reducción significativa } \\
\text { de los niveles de ansie- } \\
\text { dad y depresión frente al } \\
\text { grupo control. También } \\
\text { mejoró la calidad de vida, } \\
\text { nivel de salud global y } \\
\text { funcionamiento físico y } \\
\text { emocional. }\end{array}$ \\
\hline $\begin{array}{l}\text { Sudarshan } \\
\text { et al. } \\
2013^{(53)}\end{array}$ & $\begin{array}{l}\text { Terapia de } \\
\text { yoga }\end{array}$ & $\begin{array}{l}14 \text { mujeres con cán- } \\
\text { cer de mama esta- } \\
\text { dio I-III postcirugía. } \\
\text { Edad: } 18-70 \text { años. }\end{array}$ & $\begin{array}{l}\text { Estudio cuasiex- } \\
\text { perimental }\end{array}$ & $\begin{array}{l}12 \text { sesiones de yoga sema- } \\
\text { nales, de } 1 \text { hora de dura- } \\
\text { ción cada una. Se utilizó } \\
\text { la modalidad Hatha yoga. }\end{array}$ & No hay grupo control & $\begin{array}{l}\text { El yoga produjo mejoría de } \\
\text { ansiedad, depresión y cali- } \\
\text { dad de vida. También me- } \\
\text { joró la flexibilidad y dolor. }\end{array}$ \\
\hline $\begin{array}{l}\text { Qiu, et al. } \\
2013^{(35)}\end{array}$ & $\begin{array}{lr}\text { Grupo } & \text { de } \\
\text { terapia } & \text { cog- } \\
\text { nitivo } & \text { con- } \\
\text { ductual } & \end{array}$ & $\begin{array}{l}62 \text { mujeres con } \\
\text { cáncer de mama } \\
\text { en estadío 0-IV y } \\
\text { depresión. } 31 \text { fue- } \\
\text { ron asignadas al } \\
\text { grupo experimen- } \\
\text { tal y } 31 \text { controles } \\
\text { Edad: } 49-57 \text { años. }\end{array}$ & $\begin{array}{l}\text { Ensayo prospec- } \\
\text { tivo aleatoriza- } \\
\text { do controlado }\end{array}$ & $\begin{array}{l}\text { Se administraron } 10 \text { sesio- } \\
\text { nes semanales de } 2 \text { horas } \\
\text { cada una. El protocolo de } \\
\text { intervención fue desarro- } \\
\text { llado y modificado res- } \\
\text { pecto al manual de Aaron } \\
\text { y Judith Beck. }\end{array}$ & $\begin{array}{l}\text { El folleto que se daba } \\
\text { a los pacientes estaba } \\
\text { cubierto de tópicos } \\
\text { sobre hechos del } \\
\text { cáncer de mama, el } \\
\text { tratamiento y efectos } \\
\text { secundarios de los } \\
\text { mismos. }\end{array}$ & $\begin{array}{l}\text { La Terapia cognitivo con- } \\
\text { ductual demostró efecti- } \\
\text { vidad para el tratamiento } \\
\text { de la depresión mayor. No } \\
\text { hubo diferencia significa- } \\
\text { tiva entre ambos grupos } \\
\text { respecto a mejoría de la } \\
\text { ansiedad. }\end{array}$ \\
\hline $\begin{array}{l}\text { Groarke, } \\
2013^{(36)}\end{array}$ & $\begin{array}{l}\text { Man e jo } \\
\text { cognitivo- } \\
\text { conductual } \\
\text { del estrés }\end{array}$ & $\begin{array}{l}241 \text { mujeres con } \\
\text { cáncer de mama } \\
\text { tras } 4 \text { meses de ser } \\
\text { intervenidas qui- } \\
\text { rúrgicamente (118 } \\
\text { recibieron inter- } \\
\text { vención psicológi- } \\
\text { ca y } 123 \text { recibieron } \\
\text { solo los cuidados } \\
\text { habituales). Edad: } \\
\text { 18-75 años. }\end{array}$ & $\begin{array}{l}\text { Ensayo prospec- } \\
\text { tivo aleatoriza- } \\
\text { do controlado }\end{array}$ & $\begin{array}{l}\text { Dicha intervención traba- } \\
\text { ja aspectos como relaja- } \\
\text { ción, manejo del estrés, } \\
\text { imaginación guiada y } \\
\text { reestructuración cogniti- } \\
\text { va. Se realizó una inter- } \\
\text { vención a corto plazo: } 5 \\
\text { semanas con 3horas cada } \\
\text { una. Después se comple- } \\
\text { taba con trabajo en casa } \\
\text { diario. Los grupos se com- } \\
\text { ponen de 8-12 pacientes. }\end{array}$ & Tratamiento estándar & $\begin{array}{l}\text { Se produjo descenso de } \\
\text { niveles de ansiedad y } \\
\text { estrés en el grupo expe- } \\
\text { rimental, pero no marcó } \\
\text { estabilidad en el tiempo. } \\
\text { Estrategia especialmente } \\
\text { efectiva en pacientes con } \\
\text { aumento del estrés global. }\end{array}$ \\
\hline $\begin{array}{l}\text { Jacobsen } \\
\text { et al. } \\
2013^{(58)}\end{array}$ & $\begin{array}{l}\text { Entrenamien- } \\
\text { to autodi- } \\
\text { rigido para } \\
\text { el manejo } \\
\text { del estrés, } \\
\text { ejercicio y } \\
\text { tratamiento } \\
\text { combinado. }\end{array}$ & $\begin{array}{l}286 \text { pacientes on- } \\
\text { cológicos aleatori- } \\
\text { zados en } 4 \text { ramas } \\
\text { de tratamiento: } \\
\text { Entrenamiento en } \\
\text { manejo de estrés } \\
\text { ( } 69 \text { pacientes), } \\
\text { ejercicio ( } 62 \text { pa- } \\
\text { cientes), ambos } \\
\text { (77 pacientes) o } \\
\text { tratamiento habi- } \\
\text { tual (78 pacientes). } \\
\text { Edad: } 47-68 \text { años. }\end{array}$ & $\begin{array}{l}\text { Ensayo prospec- } \\
\text { tivo aleatoriza- } \\
\text { do controlado } \\
\text { ( } 4 \text { ramas de tra- } \\
\text { tamiento). }\end{array}$ & $\begin{array}{l}\text { El grupo de entrenamiento } \\
\text { en manejo de estrés reci- } \\
\text { bió } 15 \text { min de video, } 12 \\
\text { hojas de folleto explicativo } \\
\text { y } 30 \text { min un audio sobre } \\
\text { afrontamiento (incluían } \\
\text { información, imaginación } \\
\text { guiada, ejercicios de relaja- } \\
\text { ción muscular, etc). } \\
\text { El grupo de ejercicio reco- } \\
\text { bió } 12 \text { min video y folleto } \\
\text { de } 14 \text { hojas con guía so- } \\
\text { bre ejercicio durante la Qt } \\
\text { (recomienda ejercicios en } \\
\text { casa, como andar durante } \\
3-5 \text { veces/semana, de } 20 \text { - } \\
30 \text { minutos). } \\
\text { El grupo de ambas interven- } \\
\text { ciones recibía } 20 \text { min de } \\
\text { video y } 20 \text { hojas de folleto } \\
\text { con información mixta. }\end{array}$ & No hay grupo control & $\begin{array}{l}\text { Solo el tratamiento com- } \\
\text { binado demuestra mejoría } \\
\text { en la calidad de vida, ex- } \\
\text { clusivamente en cifras de } \\
\text { ansiedad y depresión. No } \\
\text { mejora la calidad de vida } \\
\text { a nivel físico o mental. }\end{array}$ \\
\hline
\end{tabular}




\begin{tabular}{|c|c|c|c|c|c|c|}
\hline $\begin{array}{l}\text { Lee et al. } \\
2013^{(47)}\end{array}$ & $\begin{array}{l}\text { Intervención } \\
\text { de apoyo } \\
\text { diádica entre } \\
\text { pares. }\end{array}$ & $\begin{array}{l}129 \text { pacientes } \\
\text { diagnosticados de } \\
\text { cáncer de mama } \\
\text { (estadio I-III), sien- } \\
\text { do } 64 \text { pacientes } \\
\text { del grupo expe- } \\
\text { rimental y } 65 \text { del } \\
\text { grupo control. } \\
\text { Edad: } 20-64 \text { años. }\end{array}$ & $\begin{array}{l}\text { Ensayo prospec- } \\
\text { tivo aleatoriza- } \\
\text { do controlado }\end{array}$ & $\begin{array}{l}\text { Intervención basada en la } \\
\text { teoría de la autoeficacia. } \\
\text { Cada diada se encuentra } \\
\text { una vez a la semana cara } \\
\text { a cara o por teléfono, du- } \\
\text { rante al menos } 20 \text { minutos } \\
\text { cada vez. Se encuentran } \\
\text { en cafeterías o en su do- } \\
\text { micilio para llevar a cabo } \\
\text { conversaciones sobre } \\
\text { sentimientos (ambiente } \\
\text { de apoyo para discutir } \\
\text { problemas, malestar emo- } \\
\text { cional y físico). Cada pa- } \\
\text { reja enfocará sus propios } \\
\text { intercambios. }\end{array}$ & Tratamiento estándar & $\begin{array}{l}\text { El grupo de intervención } \\
\text { experimentó una mejoría } \\
\text { significativa en senti- } \\
\text { miento de autoeficacia y } \\
\text { autogestión. La ansiedad } \\
\text { y depresión mejoran en } \\
\text { ambos grupos, no atribui- } \\
\text { ble a la intervención. }\end{array}$ \\
\hline $\begin{array}{l}\text { Garssen } \\
\text { et al. } \\
2013^{(37)}\end{array}$ & $\begin{array}{l}\text { Entre } n \text { a- } \\
\text { miento en el } \\
\text { manejo del } \\
\text { estrés }\end{array}$ & $\begin{array}{l}70 \text { mujeres con } \\
\text { cáncer de mama } \\
\text { estadio I-III }(34 \\
\text { pacientes fueron } \\
\text { asignadas al grupo } \\
\text { de intervención y } \\
36 \text { al grupo con- } \\
\text { trol). Edad: 18-75 } \\
\text { años. }\end{array}$ & $\begin{array}{l}\text { Ensayo prospec- } \\
\text { tivo aleatoriza- } \\
\text { do controlado }\end{array}$ & $\begin{array}{l}\text { Comprende } 4 \text { sesiones en } \\
\text { total durante } 35 \text { días: al } 5^{\circ} \\
\text { y } 1^{\circ} \text { precirugía y después } \\
\text { de la misma, a los } 2 \text { días } \\
\text { y al mes. Los pacientes } \\
\text { también reciben un CD } \\
\text { audio con ejercicios de } \\
\text { relajación y habilidades } \\
\text { de afrontamiento. Cada } \\
\text { sesión tenía una duración } \\
\text { de } 45-60 \text { minutos. }\end{array}$ & Tratamiento estándar & $\begin{array}{l}\text { El grupo experimental } \\
\text { presentó disminución de } \\
\text { la depresión y fatiga, pero } \\
\text { son efectos de corta dura- } \\
\text { ción (tras cirugía). No me- } \\
\text { joran la ansiedad, dolor y } \\
\text { problemas de sueño en el } \\
\text { grupo de intervención. }\end{array}$ \\
\hline $\begin{array}{l}\text { Lloyd- } \\
\text { William,et } \\
\text { al. } \\
2013^{(48)}\end{array}$ & $\begin{array}{l}\text { Intervención } \\
\text { enfocada en } \\
\text { la narrativa }\end{array}$ & $\begin{array}{l}100 \text { pacientes con } \\
\text { cáncer avanzado } \\
\text { grave, de los cua- } \\
\text { les } 49 \text { fueron al } \\
\text { grupo experimen- } \\
\text { tal y } 51 \text { al grupo } \\
\text { control. Edad: } 31- \\
89 \text { años. }\end{array}$ & $\begin{array}{l}\text { Estudio piloto } \\
\text { aleatorizado } \\
\text { controlado. }\end{array}$ & $\begin{array}{l}\text { La entrevista enfocada } \\
\text { en la narrativa consiste } \\
\text { en que el investigador } \\
\text { solicita al paciente la } \\
\text { discusión sobre su estado } \\
\text { de bienestar o sufrimiento } \\
\text { fisiológico, físico, social } \\
\text { y espiritual. Se realiza en } \\
1 \text { día. El énfasis se pone } \\
\text { en lograr que el paciente } \\
\text { cuente su propia historia. } \\
\text { Se alentaba a los pacien- } \\
\text { tes a compartir sus senti- } \\
\text { mientos. }\end{array}$ & Tratamiento estándar & $\begin{array}{l}\text { La intervención produjo } \\
\text { mejora de las cifras de an- } \\
\text { siedad y depresión. }\end{array}$ \\
\hline $\begin{array}{l}\text { Hender- } \\
\text { son, et al. } \\
2013^{(28)}\end{array}$ & $\begin{array}{l}\text { Mindfulness } \\
\text { versus pro- } \\
\text { grama edu- } \\
\text { cación nutri- } \\
\text { cional versus } \\
\text { tratamiento } \\
\text { estándar. }\end{array}$ & $\begin{array}{l}163 \text { mujeres con } \\
\text { cáncer de mama } \\
\text { estadio I-II: } 53 \text { pa- } \\
\text { cientes en grupo } \\
\text { mindfulness, } 52 \\
\text { recibiendo educa- } \\
\text { ción nutricional y } \\
58 \text { estándar. Edad: } \\
20-65 \text { años. }\end{array}$ & $\begin{array}{l}\text { Ensayo prospec- } \\
\text { tivo aleatoriza- } \\
\text { do controlado } \\
\text { en } 3 \text { brazos de } \\
\text { intervención }\end{array}$ & $\begin{array}{l}\text { El mindfulness consiste en } \\
7 \text { sesiones semanales de } \\
2,5-3,5 \text { horas/ cada una } \\
\text { y una sesión intensiva de } \\
7,5 \mathrm{~h} \text { de sesión para un } \\
\text { retiro de silencio en la } 6^{\text {a }} \\
\text { semana. } \\
\text { La educación nutricional } \\
\text { se enfoca en cambio de } \\
\text { dieta y grupo de pre- } \\
\text { paración de comidas. } \\
\text { Sigue los principios de } \\
\text { cognición social y aseso- } \\
\text { ramiento centrado en el } \\
\text { paciente. }\end{array}$ & No hay grupo control & $\begin{array}{l}\text { El grupo de mindfulness } \\
\text { experimenta reducción } \\
\text { de ansiedad, depresión } \\
\text { y hostilidad. Mejora el } \\
\text { manejo del estrés, con- } \\
\text { trol emocional y calidad } \\
\text { de vida. }\end{array}$ \\
\hline $\begin{array}{l}\text { Taso et al. } \\
2014^{(52)}\end{array}$ & $\begin{array}{l}\text { Programa de } \\
\text { ejercicios de } \\
\text { yoga }\end{array}$ & $\begin{array}{l}60 \text { mujeres con } \\
\text { cáncer de mama } \\
\text { no metastásico en } \\
\text { tratamiento con } \\
\text { quimioterapia ( } 30 \\
\text { pacientes en cada } \\
\text { grupo). Edad: } 20- \\
70 \text { años. }\end{array}$ & $\begin{array}{l}\text { Ensayo prospec- } \\
\text { tivo aleatoriza- } \\
\text { do controlado }\end{array}$ & $\begin{array}{l}\text { Programa de ejercicios de } \\
\text { yoga dos veces en semana } \\
\text { durante } 60 \text { minutos cada } \\
\text { sesión (total de } 13-16 \text { se- } \\
\text { siones administradas en } 8 \\
\text { semanas). }\end{array}$ & Tratamiento estándar & $\begin{array}{l}\text { El yoga no reduce la an- } \\
\text { siedad ni la depresión. Si } \\
\text { se redujo la fatiga }\end{array}$ \\
\hline
\end{tabular}




\begin{tabular}{|c|c|c|c|c|c|c|}
\hline $\begin{array}{l}\text { Goerling et } \\
\text { al. } 2014^{(44)}\end{array}$ & $\begin{array}{l}\text { Intervención } \\
\text { psicooncoló- } \\
\text { gica a corto } \\
\text { plazo vs. re- } \\
\text { lajación entre } \\
\text { día 3-6 posto- } \\
\text { peración. }\end{array}$ & $\begin{array}{l}45 \text { mujeres con } \\
\text { cáncer ginecoló- } \\
\text { gico (17 pacien- } \\
\text { tes reciben única } \\
\text { sesión de terapia } \\
\text { psicooncológica } \\
\text { versus } 18 \text { pacien- } \\
\text { tes con única se- } \\
\text { sión de relajación). } \\
\text { Edad: } 23-79 \text { años. }\end{array}$ & $\begin{array}{l}\text { Ensayo prospec- } \\
\text { tivo aleatoriza- } \\
\text { do controlado }\end{array}$ & $\begin{array}{l}\text { En la sesión de terapia } \\
\text { se hablaba sobre temas } \\
\text { importantes para la pa- } \\
\text { ciente, sobre la relación } \\
\text { con familiares, amigos y } \\
\text { proyectos futuros durante } \\
30 \text { minutos. }\end{array}$ & $\begin{array}{l}\text { Técnicas de relaja- } \\
\text { ción de Jacobson, en } \\
\text { procedimiento están- } \\
\text { dar de } 30 \text { minutos. }\end{array}$ & $\begin{array}{l}\text { Descenso de ansiedad en } \\
\text { ambos grupos. Descenso } \\
\text { de depresión y distrés en } \\
\text { el grupo de terapia psi- } \\
\text { cooncológica. }\end{array}$ \\
\hline $\begin{array}{l}\text { Seitz, et al. } \\
2014\end{array}$ & $\begin{array}{l}\text { Intervención } \\
\text { cognitivo- } \\
\text { conductual } \\
\text { basada en In- } \\
\text { ternet (Onco- } \\
\text { STEP) }\end{array}$ & $\begin{array}{l}20 \text { pacientes con } \\
\text { diagnóstico de } \\
\text { cáncer en la ado- } \\
\text { lescencia, actual- } \\
\text { mente en remisión. } \\
\text { Edad: } 15-19 \text { años. }\end{array}$ & $\begin{array}{l}\text { Estudio piloto } \\
\text { con una sola } \\
\text { rama de inter- } \\
\text { vención }\end{array}$ & $\begin{array}{l}\text { Basado en principios de ex- } \\
\text { presión escrita desarrolla- } \\
\text { dos por Pennebaker. Con- } \\
\text { siste en } 10 \text { sesiones con } 2 \\
\text { módulos: para reprocesar } \\
\text { la experiencia traumática } \\
\text { del cáncer y construir es- } \\
\text { trategias de afrontamiento } \\
\text { para los miedos relacio- } \\
\text { nados con el cáncer. Se } \\
\text { realiza vía mensajes escri- } \\
\text { tos en una plataforma de } \\
\text { Internet segura, mediante } \\
2 \text { sesiones semanales de } 45 \\
\text { minutos cada una, durante } \\
3 \text { meses. }\end{array}$ & Tratamiento estándar & $\begin{array}{l}\text { El grupo experimental } \\
\text { redujo los síntomas de } \\
\text { ansiedad, estrés postrau- } \\
\text { mático y el miedo a la } \\
\text { progresión del cáncer. }\end{array}$ \\
\hline $\begin{array}{l}\text { Fleming } \\
\text { et al. } \\
2014^{(32)}\end{array}$ & $\begin{array}{l}\text { Terapia } \\
\text { cognitivo- } \\
\text { conductual }\end{array}$ & $\begin{array}{l}113 \text { pacientes } \\
\text { con insomnio y } \\
\text { diagnóstico de } \\
\text { cáncer de mama, } \\
\text { próstata, vejiga o } \\
\text { ginecológico (73 } \\
\text { pacientes en grupo } \\
\text { experimental y } 40 \\
\text { en grupo control). } \\
\text { Edad: } 54-69 \text { años. }\end{array}$ & $\begin{array}{l}\text { Ensayo prospec- } \\
\text { tivo aleatoriza- } \\
\text { do controlado }\end{array}$ & $\begin{array}{l}\text { Comprende } 5 \text { sesiones se- } \\
\text { manales en pequeños gru- } \\
\text { pos de pacientes durante } \\
\text { semanas consecutivas } \\
\text { siguiendo un protocolo. }\end{array}$ & Tratamiento estándar & $\begin{array}{l}\text { Disminuyen los síntomas } \\
\text { de ansiedad, depresión, } \\
\text { fatiga e insomnio asocia- } \\
\text { dos al cáncer. }\end{array}$ \\
\hline $\begin{array}{l}\text { Font et al. } \\
2014^{(33)}\end{array}$ & $\begin{array}{l}\text { Terapia de } \\
\text { grupo psi- } \\
\text { coeducativo } \\
\text { (con TCC) }\end{array}$ & $\begin{array}{l}142 \text { mujeres con } \\
\text { diagnóstico de } \\
\text { cáncer de mama } \\
\text { no metastásico en } \\
\text { tratamiento o en } \\
\text { seguimiento (73 } \\
\text { fueron al grupo } \\
\text { control y } 69 \text { re- } \\
\text { cibieron terapia). } \\
\text { Edad: } 34-65 \text { años. }\end{array}$ & $\begin{array}{l}\text { Ensayo contro- } \\
\text { lado no aleato- } \\
\text { rizado }\end{array}$ & $\begin{array}{l}\text { Se realizaron cuatro mó- } \\
\text { dulos a lo largo de } 20 \\
\text { sesiones: ansiedad, depre- } \\
\text { sión, autoestima e } \\
\text { imagen corporal, relacio- } \\
\text { nes afectivas y sexualidad. } \\
\text { Los grupos son de 5-10p. }\end{array}$ & Tratamiento estándar & $\begin{array}{l}\text { Disminución significativa } \\
\text { de niveles de depresión } \\
\text { y la ilusión por las cosas } \\
\text { en el grupo experimental. } \\
\text { No disminuyeron signifi- } \\
\text { cativamente la ansiedad y } \\
\text { el miedo. }\end{array}$ \\
\hline $\begin{array}{l}\text { Lengacher } \\
\text { et al. } \\
2014^{(27)}\end{array}$ & Mindfulness & $\begin{array}{l}82 \text { mujeres con } \\
\text { cáncer de mama } \\
\text { post-tratamiento } \\
\text { (estadio 0-III): } 40 \\
\text { en grupo expe- } \\
\text { rimental y } 42 \text { en } \\
\text { grupo control. } \\
\text { Edad: }>55 \text { años. }\end{array}$ & $\begin{array}{l}\text { Ensayo prospec- } \\
\text { tivo aleatoriza- } \\
\text { do controlado }\end{array}$ & $\begin{array}{l}\text { Sesiones de } 2 \text { horas sema- } \\
\text { nales incluyendo } 4 \text { gra- } \\
\text { baciones de audio para } \\
\text { trabajar en casa (medita- } \\
\text { ción sentado, andando, } \\
\text { escáner corporal y yoga). } \\
\text { Los ejercicios se realizan } \\
\text { durante 15-45 minutos } \\
\text { al día durante } 6 \text { días/ se- } \\
\text { mana. Está basado en el } \\
\text { programa de Kabat-Zinn. }\end{array}$ & Tratamiento estándar & $\begin{array}{l}\text { La técnica de mindful- } \\
\text { ness redujo la ansiedad y } \\
\text { estrés percibido. Mejora } \\
\text { el funcionamiento físico. } \\
\text { Reduce el miedo a la re- } \\
\text { currencia. }\end{array}$ \\
\hline $\begin{array}{l}\text { Eyles et al. } \\
2015^{(22)}\end{array}$ & $\begin{array}{l}\text { Mindfulness } \\
\text { (MBSR) }\end{array}$ & $\begin{array}{l}19 \text { mujeres con } \\
\text { cáncer de mama } \\
\text { metastásico esta- } \\
\text { ble ( } 37-65 \text { años), } \\
\text { con esperanza de } \\
\text { vida de al menos } \\
6 \text { meses. }\end{array}$ & $\begin{array}{l}\text { Estudio clínico } \\
\text { pragmático }\end{array}$ & $\begin{array}{l}\text { Una sesión semanal a lo } \\
\text { largo de } 8 \text { semanas. Asis- } \\
\text { ten a un curso de } 7-10 \\
\text { personas/grupo. } \\
\text { Duración de } 2 \text { horas } \\
\text { aproximadamente cada se- } \\
\text { sión + 45min/día en casa. }\end{array}$ & Tratamiento estándar & $\begin{array}{l}\text { Mejoría de la ansiedad, } \\
\text { síntomas de depresión, } \\
\text { distrés emocional y ca- } \\
\text { lidad de vida en grupo } \\
\text { experimental. }\end{array}$ \\
\hline
\end{tabular}




\begin{tabular}{|c|c|c|c|c|c|c|}
\hline $\begin{array}{l}\text { Bar-Sela } \\
\text { et al. } \\
2015^{(50)}\end{array}$ & $\begin{array}{l}\text { Medicina } \\
\text { complemen- } \\
\text { taria y alter- } \\
\text { nativa }\end{array}$ & $\begin{array}{l}135 \text { pacientes con } \\
\text { cáncer primario } \\
\text { y metastásico } \\
\text { (mama, colon, pul- } \\
\text { món, páncreas y } \\
\text { otros) con edades } \\
\text { comprendidas en- } \\
\text { tre } 18 \text { y }>60 \text { años. }\end{array}$ & $\begin{array}{l}\text { Ensayo clínico } \\
\text { no aleatorizado }\end{array}$ & $\begin{array}{l}\text { Los pacientes reciben } 1 \text { te- } \\
\text { rapia semanal de uno solo } \\
\text { de los tratamientos duran- } \\
\text { te } 6 \text { semanas, de acuerdo a } \\
\text { la lista de espera y su pre- } \\
\text { ferencia (arteterapia, mu- } \\
\text { sicoterapia, imaginación } \\
\text { guiada, reiki, shiatsu, te- } \\
\text { rapia de curación cráneo- } \\
\text { sacral y unción de aceite. }\end{array}$ & Tratamiento estándar & $\begin{array}{l}\text { Se redujeron de niveles } \\
\text { moderados a bajos la an- } \\
\text { siedad, depresión, fatiga y } \\
\text { calidad de vida en el gru- } \\
\text { po experimental. }\end{array}$ \\
\hline $\begin{array}{l}\text { Lengacher } \\
\text { et al. } \\
201^{5(20)}\end{array}$ & $\begin{array}{l}\text { Mindfulness } \\
\text { (MBSR) }\end{array}$ & $\begin{array}{l}104 \text { mujeres con } \\
\text { cáncer de mama } \\
\text { estadio 0-III. Edad: } \\
23-80 \text { años. }\end{array}$ & $\begin{array}{l}\text { Ensayo prospec- } \\
\text { tivo aleatoriza- } \\
\text { do controlado }\end{array}$ & $\begin{array}{l}\text { Programa de Kabat-Zinn } \\
\text { y colegas, que condensa } \\
\text { el programa habitual en } \\
6 \text { semanas excluyendo el } \\
\text { día } 1 \text { y las } 8 \text { horas de retiro } \\
\text { de silencio. Son } 6 \text { sesiones } \\
\text { semanales de } 2 \mathrm{~h} \text { cada una. }\end{array}$ & Tratamiento estándar & $\begin{array}{l}\text { Disminuye la ansiedad, } \\
\text { depresión y mejora la } \\
\text { calidad de vida post-inter- } \\
\text { vención. También reduce } \\
\text { la fatiga, el miedo a la } \\
\text { recurrencia. }\end{array}$ \\
\hline $\begin{array}{l}\text { Grossman } \\
\text { et al. } \\
2015^{(26)}\end{array}$ & $\begin{array}{l}\text { Mindfulness } \\
\text { vs. consultas } \\
\text { telefónicas } \\
\text { piscoonco- } \\
\text { lógicas con } \\
\text { orientación } \\
\text { cognitivo- } \\
\text { conductual } \\
\text { (grupo con- } \\
\text { trol) }\end{array}$ & $\begin{array}{l}62 \text { pacientes su- } \\
\text { pervivientes de un } \\
\text { trasplante de célu- } \\
\text { las madre hema- } \\
\text { topoyéticas. Edad: } \\
\text { 38-66años. }\end{array}$ & $\begin{array}{l}\text { Ensayo prospec- } \\
\text { tivo aleatoriza- } \\
\text { do controlado }\end{array}$ & $\begin{array}{l}\text { Programa de entrena- } \\
\text { miento de } 8 \text { semanas de } \\
\text { duración, con grupos de } \\
\text { unos } 15 \text { participantes y } \\
\text { clases de } 2,5 \text { h durante } 6 \\
\text { días a la semana. Además } \\
\text { se asigna trabajo para } \\
\text { casa de } 40 \mathrm{~min} / \text { día. }\end{array}$ & $\begin{array}{l}\text { Se reciben llama- } \\
\text { das telefónicas del } \\
\text { psicooncólogo con } \\
\text { orientación psicoso- } \\
\text { cial } 2 \text { veces/mes (15- } \\
30 \text { min cada una). Se } \\
\text { habla de tópicos como } \\
\text { problemas emocio- } \\
\text { nales, familiares, de } \\
\text { autocuidado y salud } \\
\text { psicosocial. }\end{array}$ & $\begin{array}{l}\text { El Mindfulness disminuye } \\
\text { la ansiedad y depresión } \\
\text { en pacientes supervivien- } \\
\text { tes postrasplante. También } \\
\text { mejora la calidad de vida } \\
\text { y bienestar }\end{array}$ \\
\hline $\begin{array}{l}\text { Zhou et al. } \\
2015^{(55)}\end{array}$ & $\begin{array}{l}\text { Musicotera- } \\
\text { pia y entre- } \\
\text { namiento en } \\
\text { relajación } \\
\text { muscular r } \\
\text { progresiva }\end{array}$ & $\begin{array}{l}170 \text { mujeres con } \\
\text { cáncer de mama } \\
\text { postmastectomía } \\
\text { radical, rando- } \\
\text { mizadas en dos } \\
\text { grupos de } 85 \text { cada } \\
\text { uno. Edad com- } \\
\text { prendida entre } 25- \\
65 \text { años. }\end{array}$ & $\begin{array}{l}\text { Ensayo prospec- } \\
\text { tivo aleatoriza- } \\
\text { do controlado }\end{array}$ & $\begin{array}{l}\text { La musicoterapia se ad- } \\
\text { ministra dos veces al día } \\
\text { dentro de las } 48 \text { horas de } \\
\text { la cirugía de matectomía } \\
\text { radical (en la mañana } \\
\text { entre las } 6-9 \text { a.m. y en la } \\
\text { tarde de } 9-11 \text { p.m.) con } \\
30 \text { minutos por sesión } \\
\text { hasta ser dadas de alta del } \\
\text { hospital. }\end{array}$ & $\begin{array}{l}\text { La relajación se ad- } \\
\text { ministra dos veces al } \\
\text { día dentro de las } 48 \\
\text { horas de la cirugía de } \\
\text { matectomía radical } \\
\text { (en la mañana entre } \\
\text { las } 6-9 \text { a.m. y en la } \\
\text { tarde de } 9-11 \text { p.m.) } \\
\text { con } 30 \text { minutos por } \\
\text { sesión hasta ser dadas } \\
\text { de alta del hospital. }\end{array}$ & $\begin{array}{l}\text { Ambas intervenciones } \\
\text { reducen de forma impor- } \\
\text { tante la ansiedad y estrés. } \\
\text { También se reduce la du- } \\
\text { ración de la estancia en el } \\
\text { hospital. }\end{array}$ \\
\hline $\begin{array}{l}\text { Chen et al. } \\
2015^{(61)}\end{array}$ & $\begin{array}{l}\text { Ejercicio en } \\
\text { el hogar ba- } \\
\text { sado en ca- } \\
\text { minar }\end{array}$ & $\begin{array}{l}116 \text { pacientes con } \\
\text { cáncer de pulmón: } \\
58 \text { pacientes en el } \\
\text { grupo de ejercicio } \\
\text { y } 58 \text { en grupo con- } \\
\text { trol. Edad: } 37-88 \\
\text { años. }\end{array}$ & $\begin{array}{l}\text { Ensayo prospec- } \\
\text { tivo aleatoriza- } \\
\text { do controlado }\end{array}$ & $\begin{array}{l}\text { El programa de ejercicio } \\
\text { que se realiza en el do- } \\
\text { micilio, caminando con } \\
\text { una intensidad moderada } \\
\text { durante } 40 \text { minutos al día, } \\
3 \text { días a la semana y ase- } \\
\text { soramiento del ejercicio } \\
\text { semanalmente. }\end{array}$ & Tratamiento estándar & $\begin{array}{l}\text { Mejoría significativa en } \\
\text { los niveles de ansiedad y } \\
\text { depresión en el grupo ex- } \\
\text { perimental. }\end{array}$ \\
\hline $\begin{array}{l}\text { Badr et al. } \\
2015^{(46)}\end{array}$ & $\begin{array}{l}\text { Intervención } \\
\text { psicosocial } \\
\text { diádica }\end{array}$ & $\begin{array}{l}39 \text { pacientes con } \\
\text { cáncer de pulmón } \\
\text { avanzado de entre } \\
35-87 \text { años y sus } \\
\text { familiares: } 20 \text { en } \\
\text { grupo experimen- } \\
\text { tal y } 19 \text { en grupo } \\
\text { control. }\end{array}$ & $\begin{array}{l}\text { Estudio piloto } \\
\text { aleatorizado } \\
\text { controlado. }\end{array}$ & $\begin{array}{l}\text { Los manuales utilizados } \\
\text { se dividen en } 6 \text { seccio- } \\
\text { nes: autocuidado, estrés y } \\
\text { afrontamiento, manejo de } \\
\text { síntomas, comunicación, } \\
\text { resolución de problemas } \\
\text { y mantenimiento/mejora } \\
\text { de relaciones. Se partici- } \\
\text { pa conjuntamente cada } \\
\text { semana durante unas } 6 \text { en } \\
\text { total en sesiones de aseso- } \\
\text { ramiento telefónico de } 60 \\
\text { minutos de duración con } \\
\text { personal preparado. Du- } \\
\text { rante las sesiones se revisa } \\
\text { el trabajo para casa y con- } \\
\text { tenido del manual, guian- } \\
\text { do a los participantes, } \\
\text { asignando nuevas tareas } \\
\text { semanales y reforzando } \\
\text { las habilidades adquiridas. }\end{array}$ & Tratamiento estándar & $\begin{array}{l}\text { Se ha encontrado benefi- } \\
\text { cioso el trabajo con día- } \\
\text { das (paciente-cuidador) } \\
\text { ya que mejora significati- } \\
\text { vamente la ansiedad y de- } \\
\text { presión de los pacientes. } \\
\text { También aparece mejoría } \\
\text { en funcionamiento psico- } \\
\text { social de cuidadores. }\end{array}$ \\
\hline
\end{tabular}




\section{DISCUSIÓN}

A lo largo del estudio hemos encontrado que en pacientes oncológicos se detectan elevadas prevalencias de ansiedad. De hecho, como menciona Mehnert et al. ${ }^{(3)}$ es frecuente encontrar una elevada proporción de pacientes oncológicos que padecen uno o más trastornos mentales. Estos hallazgos enfatizan la importancia de proveer de intervenciones psicológicas específicas orientadas a pacientes con cáncer. El objetivo de nuestro estudio va enfocado a analizar y resumir los resultados sobre eficacia de las terapias utilizadas para la reducir la ansiedad en pacientes diagnosticados de cáncer (quedando excluidas las terapias farmacológicas).

Las estrategias terapéuticas no farmacológicas más utilizadas son: el entrenamiento en estrategias para manejar la ansiedad, la exposición gradual a los estímulos temidos, la exposición interoceptiva, las técnicas de distracción, el entrenamiento en resolución de problemas, habilidades de comunicación, reestructuración cognitiva, ventilación emocional y escucha activa ${ }^{(9)}$. La capacidad de afrontamiento de la enfermedad en pacientes con cáncer y los tratamientos médicos a los que tienen que someterse tienen profundas implicaciones en los individuos. Por ello, varias intervenciones psicológicas están enfocadas a reducir los niveles de ansiedad con el objetivo de incrementar el nivel de funcionamiento, calidad de vida y cumplimiento terapéutico ${ }^{(30)}$.

Hemos analizado 40 estudios, encontrando que sólo 34 de ellos indicaban resultados a favor del uso de técnicas para la reducción de ansiedad en pacientes oncológicos frente a 6 que informaban de la no eficacia de las intervenciones puestas a estudio.

El estudio publicado por Patsy et al. ${ }^{(8)}$, en el que se estudia la efectividad de las terapias disponibles en la actualidad para el tratamiento de la ansiedad, indica que no existe nada escrito en la bibliografía por el momento que apoye claramente recomendaciones para la práctica clínica.

En nuestra revisión, a nivel psicoterapéutico hemos podido revisar múltiples opciones terapéuticas, interesantes por la sencillez y facilidad en la administración, así como el bajo coste que pueden suponer la mayoría de ellos. Hoy en día, la técnica de Reducción de Estrés basado en Mindfulness (MBSR) se encuentra en auge y de hecho es la técnica más analizada en nuestro estudio. Dicha estrategia se ha utilizado para mejorar la aceptación de los síntomas, incrementar la capacidad meta-reflexiva y mejorar la libertad de los pacientes, la práctica del mindfulness potencia cambios en la percepción, patrones de comportamiento y de este modo la experiencia de los síntomas ${ }^{(21)}$. Nuestros resultados destacan su eficacia para lograr una mejoría significativa de la ansiedad y de los síntomas depresivos ${ }^{(20,22,26-30)}$. Como beneficios secundarios se han encontrado mejoría de la calidad de vida, del bienestar psicológico, mejor control emocional y disminución de la fatiga.

Respecto a la terapia cognitivo-conductual, tratamiento que se administra habitualmente en pacientes con ansiedad y depresión, hemos encontrado 11 estudios que encuentran efectividad cuando se utiliza en pacientes con cáncer ${ }^{(23,31-40)}$. En todos ellos se ha encontrado también otros beneficios secundarios como son mejoría de la fatiga, síntomas cognitivos y de la calidad de vida en general.

La musicoterapia es otra estrategia terapéutica utilizada con frecuencia en pacientes con cáncer. En estudios previos se ha visto que mejora la ansiedad, la depresión, la calidad de vida, la capacidad de afrontamiento de situaciones estresantes, reduce el miedo a la propia enfermedad oncológica (no incluyendo un impacto en aspectos físicos), factores que influencian sustancialmente la calidad de vida del pa- 
ciente $^{(62)}$. En nuestra revisión encontramos que es un abordaje terapéutico eficaz para reducir significativamente la ansiedad ${ }^{(56,57)}$. Cuando se combina con relajación muscular progresiva, aporta una mejoría del estado físico y psicológico durante la administración del tratamiento y una reducción de la duración de la estancia en el hospital ${ }^{(55)}$.

Otras estrategias útiles son aquellas técnicas psicoterapéuticas breves ${ }^{(44)}$, las centradas en la resolución de problemas ${ }^{(45)} y$ aquellas centradas en el significado ${ }^{(49)}$.

Mientras que el estudio de Patsy et al. ${ }^{(8)}$ encuentra que la medicina complementaria, alternativa y la meditación no son estrategias que hayan demostrado eficacia, los estudios revisados en este trabajo sobre esta temática sí parecen indicar la utilidad de estos abordajes para reducir los niveles de ansiedad, mejorar la depresión, fatiga y calidad de vida ${ }^{(50)}$. Sin embargo, el ejercicio físico también se ha encontrado eficaz para reducir la ansiedad, quizá por ser sencilla de realizar siempre que se administre de forma moderada y adaptada a la capacidad del paciente ${ }^{(61)}$. El masaje con aromaterapia también ha demostrado eficacia a corto plazo pero no se mantiene su efecto en el tiempo ${ }^{(51)}$. Por último, un estudio demuestra efectividad en la hipnosis para reducir la ansiedad, depresión, sofocos y el insomnio asociado al cáncer ${ }^{(19)}$.

Es importante destacar que seis estudios revisados $(37,42,43,47,54,60)$ indican resultados negativos en cuanto a eficacia para lograr una reducción significativa de la ansiedad. Entre ellos, encontramos el yoga, que aunque es útil para mejorar condición física del paciente (p.ej., flexibilidad) y la calidad de vida, no reduce la ansiedad de forma significativa(54). Lo mismo ocurrió con la técnica de intervención de apoyo diádica entre pares $^{(57)}$ y mediante entrevista telefónica ${ }^{(42)}$, terapia psicoeducativa ${ }^{(43)}$ y el entrenamiento en el manejo del estrés con relajación ${ }^{(37)}$.

El cáncer es una enfermedad que demanda importantes recursos y requiere de una optimización en la eficiencia de las intervenciones. El modo en que un individuo vivencia la experiencia asociada al cáncer está ciertamente ligado a sus experiencias personales y al contexto personal y social en que se encuentra el paciente al sobrevenir la enfermedad ${ }^{(63)}$. Asimismo, la experiencia asociada al cáncer está condicionada por los tratamientos posibles y por las creencias sociales respecto al cáncer en general y al tipo de cáncer en particular. Durante los últimos años el creciente conocimiento acerca de la influencia de los factores psicológicos y psicosociales en el paciente oncológico ha contribuido a generar una conciencia con respecto a su importancia en la prevención, detección y tratamiento de la enfermedad y a incluir las intervenciones psicosociales como parte integral del tratamiento oncológico ${ }^{(63)}$.

El interés del presente estudio se encuentra en la revisión de un problema muy frecuente en pacientes oncológicos y que hoy en día no tiene un tratamiento no farmacológico estandarizado. De hecho, hemos podido analizar intervenciones que son sencillas de administrar, inocuas, que suponen un bajo coste y trabajan directamente con técnicas de regulación emocional. No obstante, una de las principales limitaciones del estudio es el escaso número de publicaciones que se han encontrado. Hoy en día hay escasa evidencia y no existen recomendaciones para poder instaurarlas como otro tratamiento estándar complementario al tratamiento específico del cáncer pautado por el oncólogo. También destacar que los estudios encontrados se realizan mayoritariamente en muestras de mujeres con diagnóstico de cáncer de mama (a lo largo de todo el proceso de y estadios). Es recomendable, por lo tanto, ampliar dichos estudios a otras poblaciones de pacientes oncológicos, afectados de cánceres con distinto origen y que también se ven afectados por niveles elevados de ansiedad. 
En esta línea, sería adecuado realizar más estudios que analicen la eficacia de estas y otras técnicas en pacientes oncológicos que sufren ansiedad para poder realizar un tratamiento más adecuado y poder implementar de forma rutinaria aquellas que demuestren beneficios sustanciales.

\section{REFERENCIAS BIBLIOGRÁFICAS}

1. Virués RA. Estudio sobre ansiedad. RevistaPsicologiaCientifica.com 2005; 7(8).

2. Csizmar Carvalho C, Lopes Chaves E.C., Hollanda D, Prado Simão T, Silva Marciano Grasselli C, Giffoni Braga C. Effectiveness of prayer in reducing anxiety in cancer patients. Rev Esc Enferm USP 2014;48:684-90. Doi:10.1590/S0080623420140000400016

3. Mehnert A, Brähler E, Faller H, Härter $M$, Keller M, Schulz H. Four-week prevalence of mental disorders in patients with cancer across major tumor entities. J Clin Oncol 2014;32:3540-6. Doi: 10.1200/ JCO.2014.56.0086

4. Cano A. Control emocional, estilo represivo de afrontamiento y cáncer: Ansiedad y cáncer. Psicooncología 2005; 2:71-80.

5. Derogatis LR, Morrow GR, Fetting J, Penman D, Piasetsky S, Schmale AM et al. The prevalence of psychiatric disorders among cancer patients. JAMA 1983;249:751-7. Doi: 10.1001/jama.249.6.751

6. American Psychiatric Association, versión española López-lbor, J.J. y Valdés, $M$. (Dir.). Manual diagnóstico y estadístico de los trastornos mentales ( $4^{\text {a }}$ ed. Texto revisado). Barcelona: Masson.2002

7. Mitchell AJ, Chan M, Bhatti $H$, Halton $M$, Grassi $L$, Johansen $C$ et al. Prevalence of depression, anxiety, and adjustment disorder in oncological, haematological, and palliative-care settings: a meta-analysis of 94 interview-based studies. Lancet Oncol 2011; 12: 160-74. Doi: 10.1016/S14702045(11)70002-X

8. Patsy RS, Cope D, Sherner TL, Walker DK. Update on research-based interven- tions for anxiety in patients with cancer. Clin J Oncol Nurs 2014;18:5-16. Doi: 10.1188/14.CJON.S3.5-16.

9. Maté J, Hollenstein MF, Gil FL. Insomnio, ansiedad y depresión en el paciente oncológico. Psicooncología 2004; 1:211-30.

10. Prieto Fernández. Psicología oncológica. Revista Profesional Española de Terapia Cognitivo-Conductual 2004;2:107-20.

11. Fawzy FI. Psychosocial interventions for patients with cancer: What works and what doesn't. Eur J Cancer 1999;31:155964. Doi: 10.1016/S0959-8049(99)001914

12. Bárez M, Blasco T, Fernández Castro J. La inducción de sensación de control como elemento fundamental de la eficacia de las terapias psicológicas en pacientes de cáncer. Anales de psicología 2003;19:235-46

13. Spiegel D, Riba MB. Managing anxiety and depression during treatment. Breast J 2015;21:97-103. Doi: 10.1111/tbj.12355

14. Vinci C, Coffey SF, Norquist GS. When to recommend cognitive behavioral therapy J Fam Pract 2015;64:232-7

15. García-Jiménez, M. La Relajación para personas con cáncer. 2015. En línea. [Acceso 15 de octubre 2016]. Disponible en: http://www.cancer.net/es/node/32961.

16. Song QH1, Xu RM, Zhang QH, Ma M, Zhao XP Relaxation training during chemotherapy for breast cancer improves mental health and lessens adverse events. Int J Clin Exp Med 2013;6:979-84.

17. Rodríguez Carlos, Barrantes José Carlos, Jiménez Gabriela, Putvinski Vladimir. Manejo del dolor en el paciente oncológico. Acta Pediátr Costarric [Internet]. 2004 Jan [Acceso 18 de octubre 2016]. Disponible en: http://www.scielo.sa.cr/ scielo.php?script=sci_arttext\&pid=S1409$00902004000100001 \& \operatorname{lng}=\mathrm{en}$.

18. Luebbert K, Dahme B' Hasenbring $M$. The effectiveness of relaxation training in reducing treatment-related symptoms and improving emotional adjustment in acute non-surgical cancer treatment: A 
meta-analytical review. Psychooncology 2001;10:490-502. Doi: 10.1002/pon.537

19. Elkins G, Marcus J, Stearns V, Perfect M, Rajab $\mathrm{MH}$, Ruud C et al. Randomized trial of a hypnosis intervention for treatment of hot flashes among breast cancer survivors. J Clin Oncol 2008;26:5022-6. Doi: 10.1200/JCO.2008.16.6389

20. Lengacher CA, Kip KE, Reich RR, Craigh BM, Mogos M, Ramesar S. A Cost-effective mindfulness stress reduction program: a randomized control trial for breast cancer survivors. Nurs Econ 2015;33:.210-32.

21. Würtzen $\mathrm{H}$, Oksbjerg Dalton $\mathrm{S}$, Christensen J, Andersen KK, Elsass P, et al. Effect of mindfulness-based stress reduction on somatic symptoms, distress, mindfulness and spiritual wellbeing in women with breast cancer: Results of a randomized controlled trial, Acta Oncol 2015;54:7129. Doi: 10.3109/0284186X.2014.997371.

22. Eyles C, Leydon G.M., Hoffman C.J., Copson ER, Prescott P, Chorozoglou M. et al. Mindfulness for the self-management of fatigue, anxiety, and depression in women with metastatic breast cancer: a mixed methods feasibility study. Integr Cancer Ther 2015;14:42-56. Doi: 10.1177/1534735414546567.

23. Mattsson S, Alfonsson S, Carlsson M, Nygren $\mathrm{P}$, Olsson $\mathrm{E}$, Johansson B. U-CARE: Internet-based stepped care with interactive support and cognitive behavioral therapy for reduction of anxiety and depressive symptoms in cancer -a clinical trial protocol. BMC Cancer 2013;13:414. Doi: 10.1186/1471-2407-13-414.

24. Kennedy Sheldon L, Swanson S, Dolce A, Marsh K, Summers J. Putting evidence into practice: evidence-based interventions for anxiety. Clin J Oncol Nurs 2008;12:789-97. Doi: 10.1188/08. CJON.789-797.

25. Mehta RD, Roth AJ. Psychiatric considerations in the oncology setting. CA Cancer J Clin 2015;65:300-14. Doi: 10.3322/ caac. 21285 .
26. Grossman P, Zwahlen D, Halter JP, Passweg JR, Steiner C, Kiss A. A mindfulnessbased program for improving quality of life among hematopoietic stem cell transplantation survivors: feasibility and preliminary findings. Support Care Cancer 2015;23:1105-12. Doi: 10.1007/s00520014-2452-4.

27. Lengacher CA, Shelton MM, Reich RR, Barta MK, Johnson-Mallard V, Moscoso MS. Mindfulness based stress reduction (MBSR (BC)) in breast cancer: evaluating fear of recurrence (for) as a mediator of psychological and physical symptoms in a randomized control trial (RCT). J Behav Med 2014;37:185-95. Doi: 10.1007/s10865-012-9473-6

28. Henderson VP, Massion AO, Clemow L, Hurley TG, Druker S, Hébert JR. A randomized controlled trial of mindfulness-based stress reduction for women with earlystage breast cancer receiving radiotherapy. Integr Cancer Ther 2013;12:404-13.

29. Hoffman CF, Ersser SJ, Hopkinson JB, Nicholls PG, Harrington JE, Thomas PW. Effectiveness of mindfulness-based stress reduction in mood, breast- and endocrine-related quality of life, and wellbeing in stage 0 to iii breast cancer: A randomized, controlled trial. J Clin Oncol 2012;30;1335-42. Doi: 10.1200/ JCO.2010.34.0331

30. Bränström R, Kvillemo P, Moskowitz JT. A randomized study of the effects of mindfulness training on psychological wellbeing and symptoms of stress in patients treated for cancer at 6-month follow-up. Int J Behav Med 2012;19:535-42. Doi: 10.1007/s12529-011-9192-3

31. Seitz DCM, Knaevelsrud C, Duran G, Waadt S, Loos S, Goldbeck L. Efficacy of an internet-based cognitive-behavioral intervention for long-term survivors of pediatric cancer: A pilot study. Support Care Cancer 2014;22:2075-83. Doi: 10.1007/ s00520-014-2193-4

32. Fleming L, Randell k, Harvey C-J, Espie CA. Does cognitive behaviour therapy for 
insomnia reduce clinical levels of fatigue, anxiety and depression in cancer patients? Psychooncology 2014;23:679-84. Doi: 10.1002/pon.3468.

33. Font A, Rodríguez E. Eficacia de la terapia de grupo en cáncer de mama: Variaciones en la calidad de vida. Psicooncología 2004;1:67-86.

34. Guo Z, Tang H, Li H, Tan S, Feng K, Huang $\mathrm{YC}$ et al. The benefits of psychosocial interventions for cancer patients undergoing radiotherapy. Health Qual Life Outcomes 2013;11:121. Doi: 10.1186/14777525-11-121.

35. Qiu J, Chen W, Gao X, Xu Y, Tong H, Yang M. A randomized controlled trial of group cognitive behavioral therapy for Chinese breast cancer patients with major depression. J Psychosom Obstet Gynaecol 2013;34:60-7. Doi: 10.3109/0167482X.2013.766791.

36. Groarke AM, Curtis R, Kerin M. Cognitivebehavioural stress management enhances adjustment in women with breast cancer. Br J Health Psychol 2013;18:623-41. Doi: 10.1111/bjhp.12009

37. Garssen B, Boomsma MF, Meezenbroek EJ, Porsild T, Berkhof J, Berbee $M$, et al. Stress management training for breast cancer surgery patients. Psychooncology 2013;22:572-80. Doi: 10.1002/pon.3034

38. Greer JA, Traeger L, Bemis H, Solis J, Hendriksen ES, Park ER. A pilot randomized controlled trial of brief cognitivebehavioral therapy for anxiety in patients with terminal cancer. Oncologist 2012; 17:1337-45 Doi: 10.1634/theoncologist.2012-0041.

39. Beard C, Stason WB, Wang Q, Manola J, Dean-Clower E, Dusek JA et al. Effects of complementary therapies on clinical outcomes in patients being treated with radiation therapy for prostate cancer. Cancer. 2011;117:96-102. Doi: 10.1002/ cncr.25291.

40. Antoni $\mathrm{MH}$, Lechner S, Diaz A, Vargas $S$, Holley $H$, Phillips $K$ et al. Cognitive behavioral stress management effects on psychosocial and physiological adaptation in women undergoing treatment for breast cancer. Brain Behav Immun 2009;23:58091. Doi: 10.1016/j.bbi.2008.09.005

41. Pitceathly C, Maguire P, Fletcher I, Parle M, Tomenson B, Creed F. Can a brief psychological intervention prevent anxiety or depressive disorders in cancer patients? A randomised controlled trial. Ann Oncol 2009;20:928-34. Doi: 10.1093/annonc/mdn708.

42. Girgis A, Breen S, Stacey F, Lecathelinais C. Impact of two supportive care interventions on anxiety, depression, quality of life, and unmet needs in patients with nonlocalized breast and colorectal cancers. J Clin Oncol 2009;27:6180-90. Doi: 10.1200/ JCO.2009.22.8718.

43. Goerling U, Foerg A, Sander S, Schramm $\mathrm{N}$, Schlag PM. The impact of short-term psycho-oncological interventions on the psychological outcome of cancer patients of a surgical oncology department - A randomised controlled study. Eur J Cancer 2014;47:2009-14. Doi: 10.1016/j. ejca.2011.04.031

44. Goerling U, Jaeger C, Walz A, Stickel A, Mangler M, van der Meer E. The efficacy of short-term psycho-oncological interventions for women with gynaecological cancer: A randomized study. Oncology 2014;87:114-24. Doi: 10.1159/000362818

45. Hirai K, Motooka H, Ito N, Wada N, Yoshizaki A, Shiozaki M. Problem-Solving Therapy for psychological distress in Japanese early-stage breast cancer patients. Jpn J Clin Oncol 2012;42:1168-74. Doi: 10.1093/jjco/hys158.

46. Badr H, Smith CB, Goldstein NE, Gomez J, Redd WH. Dyadic Psychosocial intervention for advanced lung cancer patients and their family caregivers: results of a randomized pilot trial. Cancer 2015;121:150-8. Doi: 10.1097/NCC.0b013e3182642d7c.

47. Lee R, Lee KS, Oh EG, Kim SH. A Randomized trial of dyadic peer support intervention 
for newly diagnosed breast cancer patients in Korea. Cancer Nurs 2013;36:E15-22. Doi: 10.1097/NCC.0b013e3182642d7c.

48. Lloyd-Williams M, Cobb M, O'Connor C, Dunn L, Shiels C. A pilot randomised controlled trial to reduce suffering and emotional distress inpatients with advanced cancer. J Affect Disord 2013;148:141-5. Doi: 10.1016/j.jad.2012.11.013.

49. Breitbart W, Rosenfeld B, Gibson C, Pessin H, Poppito S, Nelson C et al. Centered group psychotherapy for patients with advanced cancer: a pilot randomized controIled trial. Psychooncology 2010;19:21-8. Doi: 10.1002/pon.1556.

50. Bar-Sela G, Danos S, Visel B, Mashiach T, Mitnik I. The effect of complementary and alternative medicine on quality of life, depression, anxiety, and fatigue levels among cancer patients during active oncology treatment: phase II study. Support Care Cancer 2015;23:1979-85. Doi: 10.1007/ s00520-014-2560-1

51. Wilkinson SM, Love SB, Westcombe AM, Gambles MA, Burgess CC, Cargill A et al. Effectiveness of aromatherapy massage in the management of anxiety and depression in patients with cancer: a multicenter randomized controlled trial. J Clin Oncol 2007;25:532-9. doi: 10.1200/ JCO.2006.08.9987

52. Taso CJ1, Lin HS, Lin WL, Chen SM, Huang WT, Chen SW. The effect of yoga exercise on improving depression, anxiety, and fatigue in women with breast cancer: A randomized controlled trial. J Nurs Res 2014;22:155-64. Doi: 10.1097/ jnr.0000000000000044.

53. Sudarshan M, Petrucci A, Dumitra S, Duplisea J, Wexler S, Meterissian S. Yoga therapy for breast cancer patients: A prospective cohort study. J Altern Complement Med 2013;19:227-9 2012. Doi: 10.1089/ acm.2011.0555

54. Dhruva A, Miaskowski C, Abrams D, Acree M, Cooper B, Goodman S et al. Breathing for cancer chemotherapy-asso- ciated symptoms and quality of life: Results of a pilot randomized controlled trial. J Altern Complement Med 2012;18:473-9. Doi: 10.1089/acm.2011.0555

55. Zhou K, Li X, Li J, Liu M, Dang S, Wang $D$, et al. A clinical randomized controIled trial of music therapy and progressive muscle relaxation training in female breast cancer patients after radical mastectomy: Results on depression, anxiety and length of hospital stay. Eur J Oncol Nurs 2015;19:54-9. Doi: 10.1016/j. ejon.2014.07.010.

56. Li XM1, Zhou KN, Yan H, Wang DL, Zhang YP. Effects of music therapy on anxiety of patients with breast cancer after radical mastectomy: A randomized clinical trial. J Adv Nurs 2012;68:1145-55. Doi: 10.1111/j.1365-2648.2011.05824.x.

57. Lee E-J, Bhattacharya J, Sohn C, Verres R. Monochord sounds and progressive muscle relaxation reduce anxiety and improve relaxation during chemotherapy: A pilot EEG study. Compl Ther Med 2012;20:40916. Doi: 10.1016/j.ctim.2012.07.002

58. Jacobsen PB, Phillips KM, Jim HSL, Small BJ, Faul LA, Meade CD. Effects of selfdirected stress management training and home-based exercise on quality of life in cancer patients receiving chemotherapy: a randomized controlled trial. Psychooncology 2013;22:1229-35. Doi: 10.1002/ pon.3122.

59. Loprinzi CE, Prasad K, Schroeder DR, Sood A. Stress management and resilience training (SMART) program to decrease stress and enhance resilience among breast cancer survivors: a pilot randomized clinical trial. Clin Breast Cancer 2011;11,6:364-8. Doi: 10.1016/j.clbc.2011.06.008

60. Granstam Björneklett H, Lindemalm C, Rosenblad A, Ojutkangas $\mathrm{ML}$, Letocha $\mathrm{H}$, Strang $\mathrm{P}$ et al. A randomised controlled trial of support group intervention after breast cancer treatment: Results on anxiety and depression, Acta Oncol 2012;51:198-207. Doi: 10.3109/0284186X.2011.610352 
61. Chen HM1, Tsai CM2, Wu YC3, Lin KC4, Lin CC. Randomised controlled trial on the effectiveness of home-based walking exercise on anxiety, depression and cancer-related symptoms in patients with lung cancer. Br J Cancer 2015;112:438-45. Doi: 10.1038/bjc.2014.612.
62. Pichler A, Pichler M. Music therapy in cancer patients: fact or fiction? Future Oncol 2014;10:2409-11. Doi: 10.2217/fon.14.181.

63. Barroilhet S, Forjaz MJ, Garrido E. Conceptos, teorías y factores psicosociales en la adaptación al cáncer. Actas Esp Psiquiatr 2005;33:390-7 